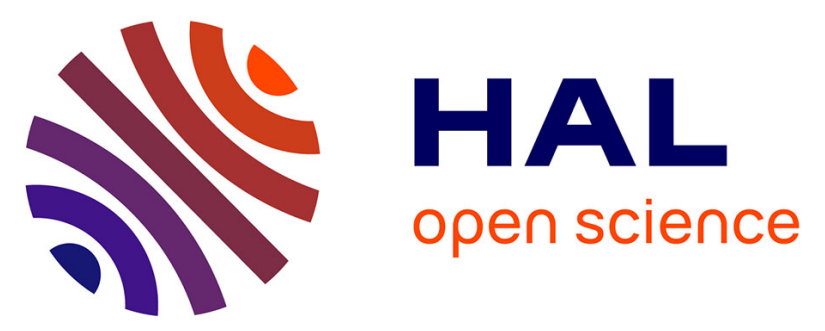

\title{
Elastic frustration triggering photoinduced hidden hysteresis and multistability in a two-dimensional photoswitchable Hofmann-like spin-Crossover metal-organic framework
}

Eric Milin, Véronique Patinec, Smail Triki, El-Eulmi Bendeif, Sébastien Pillet, Mathieu Marchivie, Guillaume Chastanet, Kamel Boukheddaden

\section{To cite this version:}

Eric Milin, Véronique Patinec, Smail Triki, El-Eulmi Bendeif, Sébastien Pillet, et al.. Elastic frustration triggering photoinduced hidden hysteresis and multistability in a two-dimensional photoswitchable Hofmann-like spin-Crossover metal-organic framework. Inorganic Chemistry, 2016, 55 (22), pp.1165211661. 10.1021/acs.inorgchem.6b01081 . hal-01407977

\section{HAL Id: hal-01407977 https://hal.science/hal-01407977}

Submitted on 2 Mar 2021

HAL is a multi-disciplinary open access archive for the deposit and dissemination of scientific research documents, whether they are published or not. The documents may come from teaching and research institutions in France or abroad, or from public or private research centers.
L'archive ouverte pluridisciplinaire HAL, est destinée au dépôt et à la diffusion de documents scientifiques de niveau recherche, publiés ou non, émanant des établissements d'enseignement et de recherche français ou étrangers, des laboratoires publics ou privés. 


\title{
Elastic Frustration Triggering Photo-Induced Hidden Hysteresis and Multistability in a Two-Dimensional Photo-Switchable Hoffman-Like Spin- Crossover Metal-Organic Framework
}

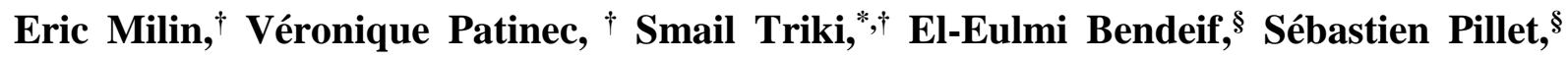 Mathieu Marchivie, $₫$ Guillaume Chastanet, $₫$ Kamel Boukheddaden"}

†UMR CNRS 6521, Chimie, Electrochimie Moléculaires, Chimie Analytique, Université de Bretagne Occidentale, 6 Avenue Victor Le Gorgeu, BP 809, 29285 Brest Cedex, France.

${ }^{\S}$ CRM2, UMR CNRS 7036, Institut Jean Barriol, Université de Lorraine, B.P. 70239, F54506 Vandoeuvre-lès-Nancy, France.

tUniversité de Bordeaux, ICMCB, 87 Av. Doc. A. Schweitzer, F-33608 Pessac, France.

"GEMaC, Université Paris-Saclay, CNRS-Université de Versailles Saint-Quentin-enYvelines, 45 Avenue des Etats-Unis 78035 Versailles cedex, France.

\begin{abstract}
:
We report a 2D Hoffman-like spin-crossover $(\mathrm{SCO})$ material $\left[\mathrm{Fe}(\operatorname{trz}-\mathrm{py})_{2}\left\{\mathrm{Pt}(\mathrm{CN})_{4}\right\}\right] .3 \mathrm{H}_{2} \mathrm{O}$, built from $\left[\mathrm{FePt}(\mathrm{CN})_{4}\right]$ layers separated by interdigitated 4-(2-pyridyl)-1,2,4,4H-triazole (trzpy) ligands. This compound exhibits an incomplete first-order SCO transition at $153 \mathrm{~K}$ between HS-HS and a HS-LS ordered state. At low temperature, it undergoes a bidirectional photo-switching to a HS-HS and LS-LS states with green and near-infrared light-irradiation, respectively, with associated
\end{abstract} T(LIESST=Light-Induced Excited SpinState Trapping) and T(reverse-LIESST) values of 52 and $85 \mathrm{~K}$, respectively. Photomagnetic investigations show that the reverse-LIESST process, performed from either HS-HS or HS-LS states, enables access to a hidden stable LS-LS state, revealing the existence of a hidden thermal hysteresis. Crystallographic

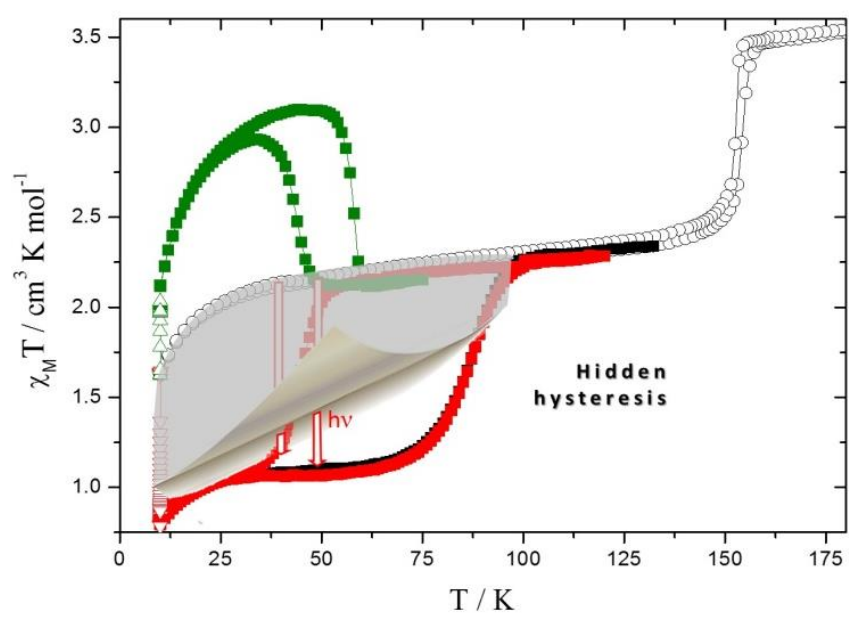
investigations allowed to identify that the strong metastability of the HS-LS state originates from the existence of a strong elastic frustration causing antiferroelastic interactions within 
the $\left[\mathrm{FePt}(\mathrm{CN})_{4}\right]$ layers, through the rigid $\mathrm{NC}-\mathrm{Pt}-\mathrm{CN}$ bridges connecting inequivalent $\mathrm{Fe}^{\mathrm{II}}$ sites. The existence of the stable LS-LS state paves the way for a multi-photo-switching and allows potential applications for electronic devices based on ternary digits.

\section{口 INTRODUCTION}

Spin crossover materials (SCO), in particular those exhibiting thermal and photo-induced magnetic bistability, are likely among the most studied switchable molecular solids in the last few years. In general, this property occurs for the first row transition metal complexes of $\mathrm{d}^{4}-\mathrm{d}^{7}$ electronic configurations when the spin pairing energy is close to the ligand field strength, producing changes in their magnetic, optical and structural properties. ${ }^{1}$ So far, the most studied examples are those based on $\mathrm{Fe}(\mathrm{II})$ ( $\mathrm{d}^{6}$ configuration), for which a paramagneticdiamagnetic transition from the high spin (HS) state $\left(\mathrm{S}=2,{ }^{5} \mathrm{~T}_{2 \mathrm{~g}}\right)$ to the low spin (LS) state (S $\left.=0,{ }^{1} \mathrm{~A}_{1 \mathrm{~g}}\right)$ is observed with temperature. ${ }^{1}$ The photo-conversion of the LS stable state into the HS metastable state has been evidenced at low temperature and shown to be reversible in some complexes. ${ }^{2}$ This allows a bidirectional photo-switching between a reference state (0) and an excited state (1) with a long lifetime, as long as the experiment is performed at lowtemperature. Going further, it is of huge interest to be able to reach different states from the same reference state, with a high contrast in at least one physical property. Such multiaddressable systems with at least three states $(0,+1,-1)$ are quite rare. ${ }^{3,4,5}$ Except the particular case of the $\left[\mathrm{Fe}(\mathrm{ptz})_{6}\right]\left(\mathrm{BF}_{4}\right)_{2}$ (ptz=1-propyltetrazole) compound for which the multistability comes from the single-molecule magnet behavior of the photo-induced metastable state, ${ }^{4}$ the observation of multi(meta)stability arises from the presence of multiple switchable sites. In the example of the binuclear system $\left\{\left[\mathrm{Fe}(\mathrm{bt})(\mathrm{NCS})_{2}\right]_{2}(\mathrm{bpm})\right\}$, irradiation in the visible range induces the population of the fully paramagnetic HS-HS state while an irradiation in the near infrared populates the intermediate HS-LS phase. ${ }^{5}$ Regarding mononuclear compound, the presence of at least two inequivalent $\mathrm{Fe}$ (II) sites can lead to a stepped spin-crossover or an incomplete transition with one iron(II) that remains in the HS state. ${ }^{3}$ Using the reverse-LIESST process, this thermally-trapped HS state can be switched to LS. From this new state, a new spin-crossover temperature can be recorded that corresponds to the spin-crossover of the second iron(II) $\operatorname{site}^{3}$ One interesting but rarely observed property is that this trapped site may undergo a first-order phase transition giving rise to a hidden thermal hysteresis, and so to a hidden bistability. ${ }^{6,7}$ 
In this context, the Brest's group and others have directed their efforts towards the so-called polymeric strategy to better control the supramolecular organization in the crystal packing and possibly to enhance cooperative effects and magnetic interactions. ${ }^{8-14}$ Such studies led to several original systems such as the SCO neutral chains based on flexible cyanocarbanion or on rigid inorganic tetracyanometallate $\left(\left[\mathrm{M}(\mathrm{CN})_{4}\right]^{2-}, \mathrm{M}=\mathrm{Ni}(\mathrm{II}), \mathrm{Pt}(\mathrm{II}), \mathrm{Pd}(\mathrm{II})\right)$ ligands which can act as polybridging ligands through their nitrile groups. ${ }^{8-10}$ In the same time, threedimensional Hoffman-like metal-organic frameworks (MOF) based on tetracynometallates anions have been extensively studied. ${ }^{12,15-17}$ However the system based on cyanocarbanion flexible ligands exhibited weak cooperativity, ${ }^{8}$ while the 3-D Hoffman-like systems displayed strong molecular cooperativity without significant photo-induced effects, even if it has been shown that these bimetallic materials can be organized on surfaces or dots for applications in molecular electronics. ${ }^{15}$ The objective of this work is the design of new systems exhibiting multi(meta)stability. So that, we extended the previous polymeric strategy to reach processable Hoffman-like MOFs ${ }^{17}$ which will help in the observation and the control of the three states $(0,+1,-1)$ configurations. Based on our achievements gained through our previous studies of SCO chains involving cyanocarbanion, cyanometallate anions, as well as 3-D Hoffman-like systems, we have extended our investigations to bimetallic systems based on $\left[\mathrm{Fe}^{\mathrm{II}} \mathrm{M}^{\mathrm{II}}(\mathrm{CN})_{4}\right]$ 2-D layers and other mono-dentate aromatic N-donor co-ligands.It is expected that the tuning of the flexibility/rigidity of the co-ligands which play a crucial role in the propagation of the acoustic waves, through which the interaction between spin-crossover units takes place. This would allow the control of the interlayer interactions, resulting in significant changes in the properties of the thermal (transition temperature and/or thermal hysteresis loop) and photo-induced (photo-induced effects, LIESST temperature and subsequent relaxation curves) transition regimes of the SCO material. ${ }^{14}$ At this end, and since the 2-D SCO based on Hoffman-like frameworks are, up to now, essentially limited to pyridyl $\mathrm{N}$-donor ligands, we focus here our investigations on other aromatic $\mathrm{N}$-donor ligands such as functionalized azole ligands involving two or more $\mathrm{N}$-donor atoms.

So, we report herein the synthesis, the thermal variation of the crystallographic structural data and magnetic properties of the SCO 2-D Hoffman-like system [Fe(trzpy) $\left.{ }_{2}\left\{\mathrm{Pt}(\mathrm{CN})_{4}\right\}\right] .3 \mathrm{H}_{2} \mathrm{O}$ (1) (trz-py = 4-(2-pyridyl)-1,2,4,4H-triazole), based on the N-donor functionalized triazole ligand. The photo-switching processes involved in this multi(meta)stable and bidirectional photo-switching Hoffman-type MOF, are discussed in the light of full photomagnetic and photo-crystallographic investigations. The magnetic properties of 1 reveal an incomplete spin transition leading to an ordered HS-LS configuration 
at low temperature. This state can be either switched by light irradiation, using an adequate wavelength, to HS-HS or LS-LS configurations whose thermal stabilities have been analyzed. An original result brought in the present work lies with the clear identification of the elastic frustration within the Fe-Pt-Fe-Pt pseudo-squares as the physical origin of the incomplete spin transition, in excellent agreement with very recent theoretical predictions. ${ }^{18}$ It should pointed out that recently, the coordination polymer $\left[\mathrm{Fe}(\text { thtrz })_{2} \mathrm{Pd}(\mathrm{CN})_{4}\right] \cdot(\mathrm{EtOH})\left(\mathrm{H}_{2} \mathrm{O}\right)$ (thtrz $=\mathrm{N}-$ thiophenylidene-4H-1,2,4-triazol-4-amine) was communicated as the first 2-D Hoffman-like SCO coordination polymer based on triazole ligands, which revealed a complete two-steps conversion. ${ }^{19}$

\section{口 RESULTS AND DISCUSSION}

Compound 1 has been prepared as polycrystalline powder by adding $\mathrm{K}_{2}\left[\mathrm{Pt}(\mathrm{CN})_{4}\right] \cdot x \mathrm{H}_{2} \mathrm{O}$ to an aqueous solution containing 4-(2-pyridyl)-1,2,4,4H-triazole and iron (II) perchlorate in 1:2:1 ratio, respectively. The corresponding single crystals suitable for X-ray diffraction have been obtained using diffusion technique in fine glass tube $(3.0 \mathrm{~mm}$ diameter) by carefully layering an aqueous solution containing 4-(2-pyridyl)-1,2,4,4H-triazole and iron (II) perchlorate onto an aqueous solution of $\mathrm{K}_{2}\left[\mathrm{Pt}(\mathrm{CN})_{4}\right] . x \mathrm{H}_{2} \mathrm{O}$. The room-temperature X-ray powder diffraction spectrum (XRPD) of the polycrystalline powder has been performed to confirm the isomorphism of the powders by comparison with the simulated XRPD pattern for the corresponding single crystal sample. As clearly indicated by Figure S1, the measured pattern of microcrystalline powder of $\mathbf{1}$ is indeed qualitatively similar to the pattern calculated from the single-crystal crystallographic data. The absence of any non-crystalline impurities in this powder has been confirmed by IR spectroscopy which showed that the spectrum of the single crystals is identical to that observed for the white powder of $\mathbf{1}$ (see Figures S2 and S3). The IR spectrum of 1 shows sharp peaks attributed to the distinctive bond vibration modes of the trzpy molecule. Except the bands attributed to the $\left[\mathrm{Pt}(\mathrm{CN})_{4}\right]^{2-}$ anion (Figure S4), the IR spectrum of $\mathbf{1}$ is similar to that measured for the free trz-py molecule (see $1600-400 \mathrm{~cm}^{-1}$ region in Figures S2 and S3). Thus, this observation does not allow any direct conclusion on the coordinating character of this organic ligand. However, the blue shift of the characteristic intense C-N stretching band $v_{(\mathrm{CN})}$ observed at $2167 \mathrm{~cm}^{-1}$, which was located at 2133 and 2122 $\mathrm{cm}^{-1}$ in $\mathrm{K}_{2}\left[\mathrm{Pt}(\mathrm{CN})_{4}\right] \cdot x \mathrm{H}_{2} \mathrm{O}$ (See Figure S4), reveals the $\mu_{4}$-bridging coordination mode of the $\left[\mathrm{Pt}(\mathrm{CN})_{4}\right]^{2-}$ moiety in compound 1. In the low frequency region, the strong asymmetric doublet, observed at 229 and $225 \mathrm{~cm}^{-1}$, is assigned to the $\mathrm{Fe}-\mathrm{N}$ stretching vibrations in 
agreement with the presence of HS Fe(II) centers at room temperature. The existence of two distinct bands is indicative of the two types of Fe-N bond lengths as revealed by the crystal structure determination (see below). ${ }^{20}$

The magnetic susceptibility $\left(\chi_{m}\right)$ for $\mathbf{1}$ was determined over the 2-300 K temperature range on a polycrystalline sample. The $\chi_{m} T$ versus $T$ plot (where $T$ is the temperature) is displayed in Figure 1a. In the high-temperature region, the $\chi_{m} T$ value $\left(3.51 \mathrm{~cm}^{3} \cdot \mathrm{K} \cdot \mathrm{mol}^{-1}\right)$ is consistent with a HS ( $\mathrm{S}=2$ ) configuration of the hexacoordinated Fe(II) ions.
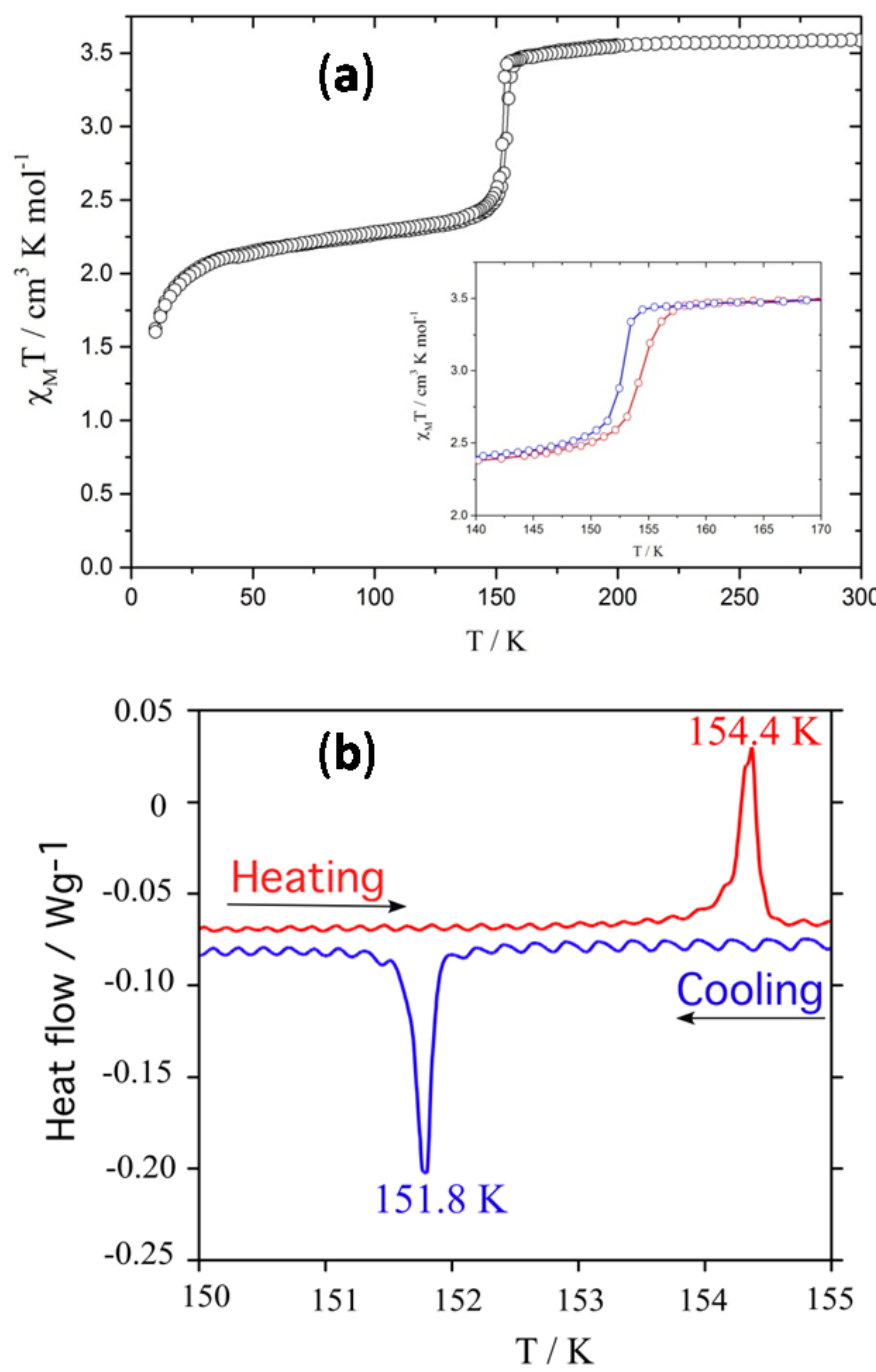

Figure 1. (a) Thermal dependence of the $\chi_{\mathrm{m}} \mathrm{T}$ product for $\mathbf{1}$ showing the abrupt incomplete spin transition around $153 \mathrm{~K}$. Inset shows an enlarged view of the transition region showing the first-order character of the thermal dependence of the $\chi_{\mathrm{m}} \mathrm{T}$ product, which is accompanied with a $\sim 2 \mathrm{~K}$ wide hysteresis loop; (b) DSC study for $\mathbf{1}$ showing the exo- and endo-thermic transitions. The upper and lower transition temperatures, determined from the maximum of the enthalpic peaks (154.4 and $151.8 \mathrm{~K})$, are in excellent agreement with those of magnetic data. Temperature scan rate was, $0.4 \mathrm{~K} \cdot \mathrm{min}^{-1}$.

Upon cooling, $\chi_{m} T$ remains almost constant down to ca. $153 \mathrm{~K}$, at which it abruptly decreases to ca. $2.0 \mathrm{~cm}^{3} \cdot \mathrm{K}^{\prime} \mathrm{mol}^{-1}$, indicating the presence of an incomplete sharp HS to LS SCO first- 
order phase transition. Below $150 \mathrm{~K}$, the $\chi_{m} T$ product remains almost constant with a residual fraction of ca. $57 \% \mathrm{Fe}(\mathrm{II})$ ions in the HS configuration. This $\chi_{m} T$ value is slightly higher than half of the high temperature value, $3.51 \mathrm{~cm}^{3} \cdot \mathrm{K} \cdot \mathrm{mol}^{-1}$, because of the presence of a paramagnetic fraction of ca. $7 \%$, probably arising from a small paramagnetic residue or a dehydrated phase. ${ }^{21}$ At very low temperatures, the fraction of HS Fe(II) ions shows the usual zero field splitting (ZFS) effect leading to a decrease of $\chi_{m} T$ product. The warming mode shows a slight thermal hysteresis as the spin transition temperatures $\left(T_{1 / 2}\right)$ for the cooling $\left(T_{1 / 2}^{\text {down }}\right)$ and warming $\left(T_{1 / 2}^{\text {up }}\right.$ ) modes are 152 and $154 \mathrm{~K}$, respectively (see inset of Figure 1a), for a temperature scan rate of $0.4 \mathrm{~K} \cdot \mathrm{min}^{-1}$. This bistability was clearly confirmed by DSC studies in which the thermal variation of the heat flow shows exo- and endo-thermic transitions at 151.8 and $154.4 \mathrm{~K}$, respectively (Figure 1b). Furthermore, we found that the phase transition occurs with an enthalpy and entropy changes of $\Delta \mathrm{H}=4.8 \mathrm{~kJ}^{\mathrm{mol}}{ }^{-1}$ and $\Delta \mathrm{S}=$ $30 \mathrm{~J} . \mathrm{K}^{-1} \cdot \mathrm{mol}^{-1}$, respectively. These values are in good agreement with those reported in the literature for SCO compounds. ${ }^{22}$

Based on the conclusions derived from the thermal variation of the magnetic data and from the calorimetric measurements, the crystal structure of $\mathbf{1}$ has been determined at $296 \mathrm{~K}$ and $120 \mathrm{~K}$. The relevant structural modifications induced by light irradiation at $10 \mathrm{~K}$ will be detailed in the following sections. Compound $\mathbf{1}$ crystallizes in the monoclinic $\mathrm{C} 2 / \mathrm{c}$ space group. Crystallographic data, selected bond lengths and angles are listed in Tables S1 and Table 1, respectively. The crystal structure of $\mathbf{1}$ is built from two crystallographically independent $\mathrm{Fe}$ (II) sites, Fe1 and Fe2, respectively located on an inversion center ( $1 / 1 / 4-1 / 4$ 1/2 $)$ and a two-fold axis $(1 / 2 \mathrm{~b} 3 / 4)$, one $\left[\mathrm{Pt}(\mathrm{CN})_{4}\right]^{2-}$ anion, two monodentate trz-py ligands and three water solvent molecules located on general positions (Figure 2).

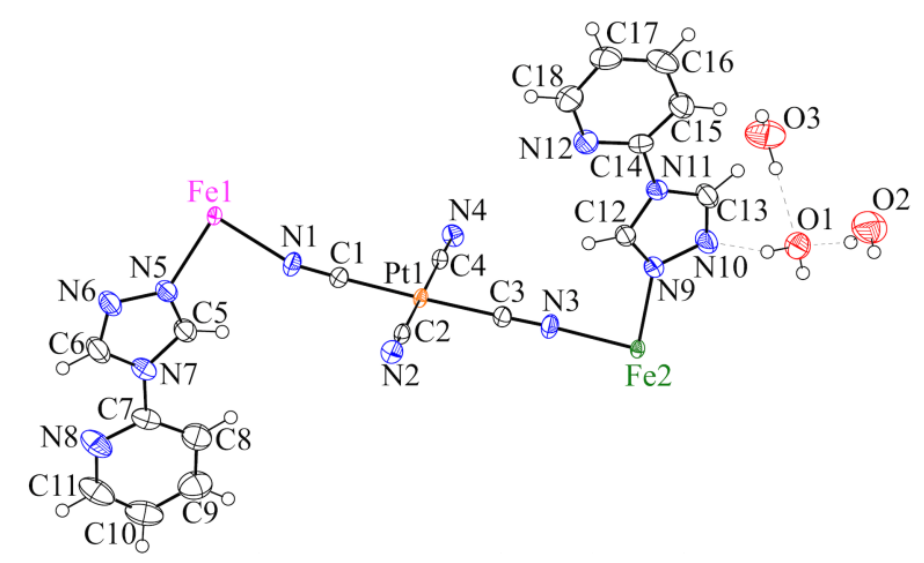

Figure 2. Thermal ellipsoid drawing (30\% probability ellipsoids) of the asymmetric unit of $\mathbf{1}$ at $296 \mathrm{~K}$ showing the labeling scheme. 
Table 1. Selected bond lengths and distortion parameters of the coordination sphere of compound 1.

\begin{tabular}{|c|c|c|c|c|c|}
\hline $\mathrm{Fe}-\mathrm{N}$ & \multicolumn{5}{|c|}{ distance / $\AA$} \\
\hline & 296 K HS1 & $120 \mathrm{KIP} 1$ & $10 \mathrm{KIP} 2$ & $10 K L S$ & $10 K H S 2$ \\
\hline Fe1-N1 & $2.143(2)$ & $1.943(3)$ & $1.944(8)$ & $1.939(3)$ & $2.128(7)$ \\
\hline $\mathrm{Fe} 1-\mathrm{N} 2^{1}$ & $2.162(2)$ & $1.944(2)$ & $1.933(7)$ & $1.947(3)$ & $2.148(7)$ \\
\hline Fe1-N5 & $2.178(2)$ & $1.974(2)$ & $1.984(5)$ & $1.976(3)$ & $2.183(6)$ \\
\hline$\langle\mathrm{Fe} 1-\mathrm{N}\rangle$ & $2.161(2)$ & $1.954(2)$ & $1.954(7)$ & $1.954(3)$ & $2.153(7)$ \\
\hline $\mathrm{Fe} 2-\mathrm{N} 3$ & $2.141(2)$ & $2.140(3)$ & $2.146(7)$ & $1.939(3)$ & $2.127(7)$ \\
\hline $\mathrm{Fe} 2-\mathrm{N} 4^{2}$ & $2.151(2)$ & $2.151(2)$ & $2.132(8)$ & $1.956(3)$ & $2.143(7)$ \\
\hline Fe2-N9 & $2.209(2)$ & $2.188(2)$ & $2.191(5)$ & $1.996(3)$ & $2.201(6)$ \\
\hline \multirow[t]{2}{*}{$\langle\mathrm{Fe} 2-\mathrm{N}\rangle$} & $2.167(2)$ & $2.160(2)$ & $2.156(7)$ & $1.964(3)$ & $2.157(7)$ \\
\hline & \multicolumn{5}{|c|}{ Distortion $/^{\circ}$} \\
\hline${ }^{\mathrm{a}} \Sigma(\mathrm{Fe} 1)\left(\left(^{\circ}\right)\right.$ & $7(1)$ & $7(1)$ & $5(3)$ & $12(3)$ & $6(3)$ \\
\hline${ }^{\mathrm{b}} \Theta(\mathrm{Fe} 1)\left(^{\circ}\right)$ & $18(2)$ & $22(2)$ & $13(2)$ & $34(2)$ & $19(2)$ \\
\hline$\Sigma(\mathrm{Fe} 2)\left({ }^{\circ}\right)$ & $15(1)$ & $19(1)$ & $21(3)$ & $12(3)$ & $18(3)$ \\
\hline$\Theta(\mathrm{Fe} 2)\left(^{\circ}\right)$ & $46(2)$ & $52(2)$ & $53(2)$ & $37(2)$ & $57(2)$ \\
\hline
\end{tabular}

${ }^{1} 1 / 2-x, 1 / 2-y, 1-z ;{ }^{2} 1-x, 1+y, 3 / 2-z .{ }^{a} \sum$ is the sum of the deviation from $90^{\circ}$ of the 12 cis-angles of the $\mathrm{FeN}_{6}$ octahedron; ${ }^{23 \mathrm{a}}{ }^{\mathrm{b}} \Theta$ is the sum of the deviation from $60^{\circ}$ of the 24 trigonal angles of the projection of the $\mathrm{FeN}_{6}$ octahedron onto its trigonal faces. ${ }^{23 \mathrm{~b}}$

The Fe1 and $\mathrm{Fe} 2$ iron centers are alternately linked by $\left[\mathrm{Pt}(\mathrm{CN})_{4}\right]^{2-}$ anions to form a 2-D coordination polymer within corrugated layers corresponding to the $\mathrm{a}+\mathrm{c}$ and $\mathrm{b}$ directions. The 2-D network can be described as a succession of $\mathrm{Fe}_{4}$ pseudo-squares which diagonals are formed by $\mathrm{Fe} 1-\mathrm{Pt} 1-\mathrm{Fe} 2$ bridges leading to an alternation of $\mathrm{Fe} 1$ and $\mathrm{Fe} 2$ along the a+c direction (Figure 3a). As NC-Pt-CN bridges are a little longer than the pseudo squares diagonals, the $\left[\mathrm{Pt}(\mathrm{CN})_{4}\right]^{2-}$ moieties lie slightly out of the plane, leading to the corrugation of the 2D layers by a tilt of the $\mathrm{FeN}_{4}$ planes around $\mathrm{Fe} 1$ (Figure 3b). The 2D layers are furthermore stacked along the a-c direction; the cohesion of the crystal network is assisted in this direction by $\pi-\pi$ interactions between the trz-py ligands and a strong hydrogen-bonding network that involves the three water molecules and the non coordinated nitrogen atom of the triazole group of the trz-py ligand (Tables S2 and S3; Figures 4 and S5). 

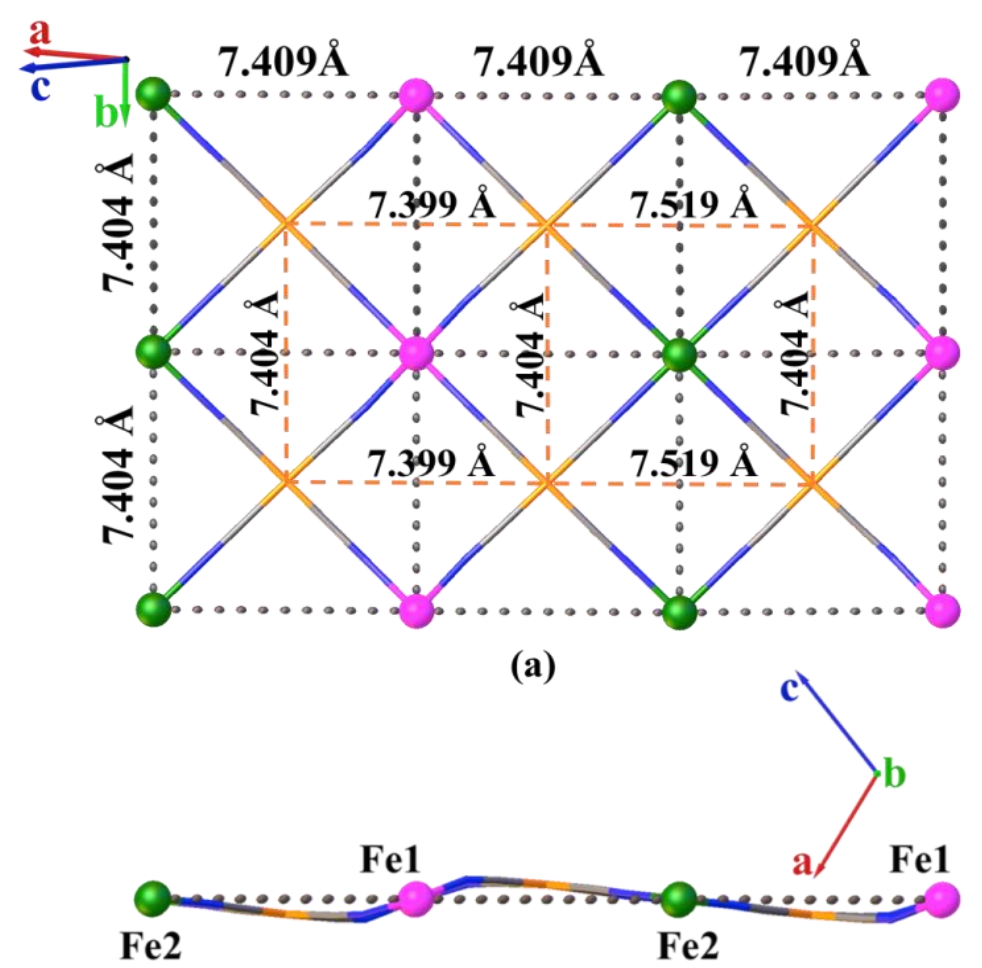

(b)

Figure 3. View of the 2D arrangement of 1 at $296 \mathrm{~K}$ : (a) Projection along the [-1 01 1 direction showing the $\mathrm{Fe}_{4}$ pseudo-squares; (b) view along the $\left[\begin{array}{lll}0 & 1 & 0\end{array}\right]$ direction showing the tilted $\mathrm{Fe} 1 \mathrm{~N}_{4}$ planes. $\mathrm{Fe} 1$ and $\mathrm{Fe} 2$ atoms are respectively drawn in purple and green, $\mathrm{N}$ in blue, $\mathrm{C}$ in grey and $\mathrm{Pt}$ in orange.

It is worth to note that the hydrogen bonding network links only the trz-py ligands which are coordinated to the Fe 2 centers (Figure 4b). At $296 \mathrm{~K}$, the two iron sites present an octahedral geometry involving an $\mathrm{FeN}_{4}$ equatorial plane arising from four nitrogen atoms of the $\left[\mathrm{Pt}(\mathrm{CN})_{4}\right]^{2-}$ anion and two $\mathrm{N}$ atoms in axial positions from the trz-py ligands.

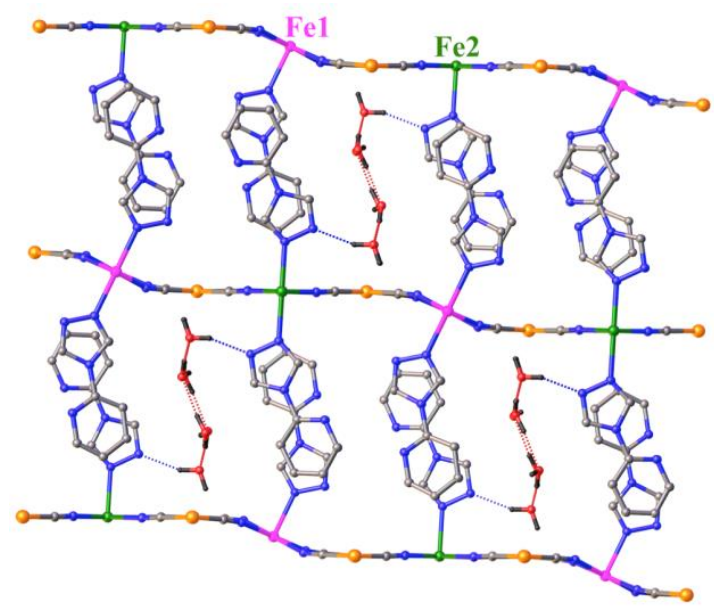

(a)

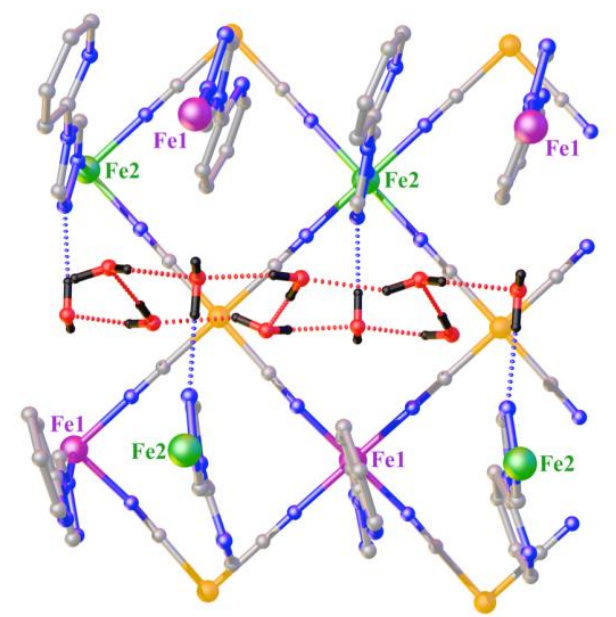

(b)

Figure 4. 3D crystal packing of 1 at ambient temperature (296 K): (a) view along the [0 10 l 0 ] direction; (b) view along the [ $\left.\begin{array}{lll}2 & 0 & -1\end{array}\right]$ direction showing the hydrogen-bonding network (dashed lines) between Fe2 sites. 
As shown in Table 1, the mean Fe2-N distance $2.167(2) \AA$, is slightly longer than the mean Fe1-N distance, 2.161(2). A difference mainly due to the Fe-N(trz-py) bonds (Fe1-N5 = 2.178(2) $\AA$ and Fe2-N9 = 2.209(2) $\AA$ ). A meticulous inspection of the bond distances reveals a more distorted coordination sphere for the Fe2 ion (Table 1), ${ }^{23}$ which then experiences a significant elastic strain. According to the mean Fe-N distances, both iron centers are in the HS state at 296K. Nevertheless, the distortion of the octahedral geometries are found very small in the HS state for both metal centers, as usually observed for "Hoffman like" spin crossover compounds. ${ }^{13,17}$ The equatorial plane for $\mathrm{Fe} 2$ is found aligned with that of the $\left[\mathrm{Pt}(\mathrm{CN})_{4}\right]^{2-}$, while it deviates significantly by $24.8^{\circ}$ for $\mathrm{Fe}$, leading to a corrugation of the $2 \mathrm{D}$ network (Figure 5). At $120 \mathrm{~K}$, the octahedral geometries of the two iron atoms are significantly different. While the Fe2 environment remains almost unchanged, the Fe1-N bond lengths drastically decrease to reach a mean value of 1.954(2) $\AA$. This feature is the signature of the change of the spin state of $\mathrm{Fe} 1$ from HS to LS at low temperature while $\mathrm{Fe} 2$ remains trapped in the HS state, most probably due to the above mentioned higher distortion of its coordination sphere known to favor the HS state. ${ }^{23}$

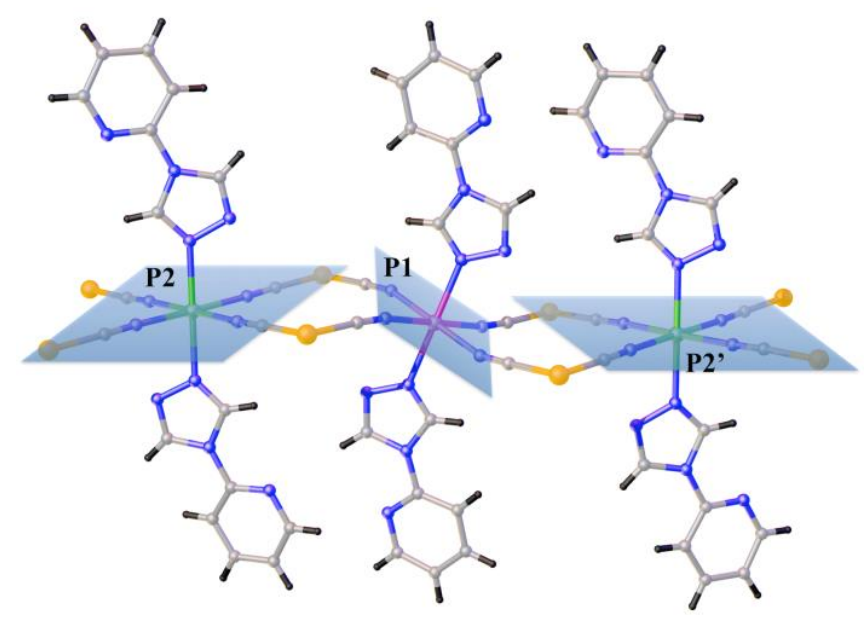

Figure 5. View along the $\left[\begin{array}{lll}0 & 1 & 0\end{array}\right]$ direction at ambient temperature $(296 \mathrm{~K})$ showing the $\mathrm{FeN} 4$ equatorial plane aligned with the $\left[\mathrm{Pt}(\mathrm{CN})_{4}\right]^{2-}$ plane for $\mathrm{Fe} 2\left(\mathrm{P} 2\right.$ and $\mathrm{P} 2$ ') while $\mathrm{Fe} 1 \mathrm{~N}_{4}$ plane (P1) appears clearly tilted.

The angular octahedral geometry of Fe1 is already very regular in the HS state, and therefore does not regularize further during the spin transition as shown by the distortion parameters (see Table 1) that remain almost unchanged between 296 and $120 \mathrm{~K}$. Such a behavior is typical for "Hoffman like" systems. ${ }^{13,17}$ The $\mathrm{FeN}_{4}$ equatorial plane remains in the $\left[\mathrm{Pt}(\mathrm{CN})_{4}\right]^{2-}$ plane for $\mathrm{Fe} 2$ while the deviation from this plane is still significant for $\mathrm{Fe} 1$ (deviation angle = $21.7^{\circ}$ ) but less pronounced than that observed at room temperature $\left(24.8^{\circ}\right)$ (Figure 5). These structural features result in an antiferroelastic interaction between the two types of metal 
centers that prevents the spin transition of $\mathrm{Fe} 2$ that remains trapped HS and explain therefore the magnetic behavior below 150K. Such elastic interactions are illustrated by Figures S6 and $\mathrm{S} 7$ that show the deformation of the $\mathrm{Fe}_{4}$ pseudo-squares in the low-temperature region. While the $\mathrm{Fe}_{4}$ squares appear very regular at room temperature (Figure 3a), they progressively distort at $120 \mathrm{~K}$ to reach a pseudo rectangular geometry (Figure S6). The inter-layer distances observed at $120 \mathrm{~K}$ are similar to those observed at room temperature but with systematically shorter distances, which is a characteristic of the natural thermal contraction (Tables S2 and S3).

Photomagnetic properties were first studied on the polycrystalline sample at $10 \mathrm{~K}$. From the intermediate HS-LS state, a photo-excitation with green light (510 nm), after $30 \mathrm{~min}$ of irradiation, induces an increase of the $\chi_{m} T$ product from 1.64 to $2.10 \mathrm{~cm}^{3} \cdot \mathrm{K}^{\prime} \mathrm{mol}^{-1}$ (Figure 6). This reveals the occurrence of LIESST effect and the photo-transformation of LS species into HS, thus leading to a sizeable population of neighboring molecules in the HS-HS configuration. Applying the usual T(LIESST) procedure, ${ }^{24}$ that is a warming in the dark at 0.3 $\mathrm{K} \cdot \mathrm{min}^{-1}$, the $\chi_{m} T$ curves increases up to $3.11 \mathrm{~cm}^{3} \cdot \mathrm{K} \cdot \mathrm{mol}^{-1}$ at $42 \mathrm{~K}$. This increase is due to the zero-field splitting of the two iron(II) HS. Therefore, the maximum reached gives insight on the photo-conversion efficiency of $\sim 90 \%$. Upon further warming in the dark, the $\chi_{m} T$ product decreases rapidly, due to thermal relaxation, to recover the value of the intermediate state. The derivative of the curve indicates a T(LIESST) value of $52 \mathrm{~K}$.

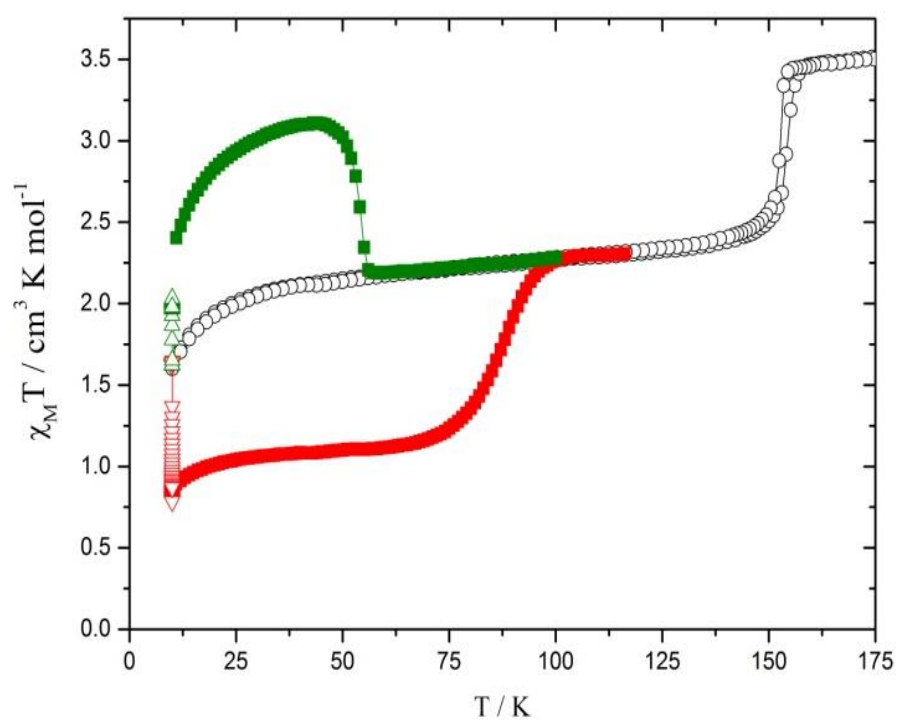

Figure 6. Thermal evolution of the $\chi_{m} T$ product from high temperature to low temperature in the dark (o); under $510 \mathrm{~nm}(\Delta)$ and $830 \mathrm{~nm}(\nabla)$ light irradiations at $10 \mathrm{~K}$. Green $(\square)$ and red ( $\square$ ) squares are the subsequent thermal relaxations in the dark. The temperature sweep rate was $0.4 \mathrm{~K} \cdot \mathrm{min}^{-1}$. Used power intensity was $6 \mathrm{~mW} . \mathrm{cm}^{-2}$ ). 
A set of relaxation kinetics were recorded in the dark at several temperatures to derive the physical parameters (activation energy, interaction strength and frequency factor) governing the relaxation of the photo-induced metastable HS fraction (Figure S8). We found that the relaxation curves follow a sigmoidal behavior, in agreement with the cooperative character of the thermal spin transition. To extract the relaxation rate constant at each temperature, we have considered the self-accelerated Hauser's model, ${ }^{25}$ whose physical origin and mean-field character were demonstrated in Ref. 26. In this model, the time dependence of the photoconverted HS fraction, $\gamma_{\mathrm{HS}}$, follows the macroscopic master equation:

$$
\mathrm{d} \gamma_{\mathrm{HS}} / \mathrm{d} t=-\gamma_{\mathrm{HS}} \mathrm{k}_{\mathrm{HL}}\left(\mathrm{T}, \gamma_{\mathrm{HS}}\right)
$$

where $t$ stands for time, and $\mathrm{k}_{\mathrm{HL}}\left(\mathrm{T}, \gamma_{\mathrm{HS}}\right)$ is the relaxation rate from $\mathrm{HS}$ to LS, which depends non-linearly (due to cooperative effects) on the HS fraction as follows:

$$
\left.\mathrm{k}_{\mathrm{HL}}\left(\mathrm{T}, \gamma_{\mathrm{HS}}\right)=\mathrm{k}^{0}{ }_{\mathrm{HL}}(\mathrm{T}) \cdot \exp \left[\left(1-\gamma_{\mathrm{HS}}\right) \cdot \mathrm{E}_{\mathrm{a}} * / \mathrm{k}_{\mathrm{B}} \mathrm{T}\right] \quad \text { (eq. } 2\right)
$$

where the pre-exponential factor, $\mathrm{k}^{0}{ }_{\mathrm{HL}}(\mathrm{T})=\mathrm{k}_{\infty} \cdot \exp \left(-\mathrm{E}_{\mathrm{a}}^{0} \mathrm{a} / \mathrm{k}_{\mathrm{B}} \mathrm{T}\right)$ is the relaxation rate in the HS state $\left(\gamma_{\mathrm{HS}}=1\right), \mathrm{E}_{\mathrm{a}}$ the corresponding energy barrier, $\mathrm{k}_{\infty}$ is the "spin flip" frequency from HS to LS at infinite temperature and $\mathrm{E}_{\mathrm{a}}{ }^{*}$ is an effective parameter accounting for the interactions between the SCO units, assumed in this simple model as uniform and temperatureindependent. We used this model and fitted all experimental relaxation curves of Figure S8, on which we have superimposed the theoretical findings (red lines). The obtained parameter values of the refinement are summarized in Table S4. An excellent agreement is found between the simulation and the experimental data. The following values of the thermodynamic parameters $\mathrm{E}_{\mathrm{a}}^{0}=590(18) \mathrm{K}, \mathrm{k}_{\infty}=8.2 \mathrm{~s}^{-1}$ and $\mathrm{E}_{\mathrm{a}}{ }^{*} \sim 180(18) \mathrm{K}$ were extracted from the Arrhenius plot (ln $k_{H L}$ vs 1/T, inset Figure S8). To judge the relevance of these data, we compared them to those of heat capacity measurements. The effective energy barrier $E_{a}\left(\gamma_{H S}\right)=E_{a}^{0}-E_{a} *\left(1-\gamma_{H S}\right)$ is exactly equal to the enthalpy of transformation for $\gamma_{H S}=1 / 2$. According to current photomagnetic data, we derive $\mathrm{E}_{\mathrm{a}}\left(\gamma_{\mathrm{HS}}=1 / 2\right) \sim 500 \mathrm{~K}$ per site, which gives an enthalpy change at the transition of $\sim 4.2 \mathrm{~kJ} \cdot \mathrm{Mol}^{-1}$ that compares well to the $\Delta \mathrm{H}=4.8$ $\mathrm{kJ} \cdot \mathrm{Mol}^{-1}$ obtained from heat capacity measurements. At $10 \mathrm{~K}$, irradiation of the HS-LS state in the near-infrared region $\left(830 \mathrm{~nm}\right.$ ) during $60 \mathrm{~min}$ (Figure 6) induces a decrease of $\chi_{m} T$ product from 1.64 to $0.82 \mathrm{~cm}^{3} \cdot \mathrm{K}^{\prime} \mathrm{mol}^{-1}$, indicating the occurrence of reverse-LIESST effect and the presence of a sizeable population of neighboring molecules in the LS-LS configuration. We could not reach the pure LS state probably due to absorption of light inside the sample. Applying the T(LIESST) procedure again, the $\chi_{m} T$ curves, measured in the dark, slightly increase up to a plateau of around $1.1 \mathrm{~cm}^{3} \cdot \mathrm{K} \cdot \mathrm{mol}^{-1}$ between 30 and $60 \mathrm{~K}$ (Figure 6). This slight increase is attributed to the zero-field splitting (zfs) of the non-transformed fraction of 
HS Fe 2 centers. Upon further warming, the $\chi_{m} T$ product increases to recover the value of the intermediate state at $\sim 100 \mathrm{~K}$. The derivative of the curve indicates a T(reverse-LIESST) value of $85 \mathrm{~K}$. The stability of this photo-excited state has been checked through a detailed study of the relaxation kinetics at different temperatures. After irradiation at $10 \mathrm{~K}$ at $830 \mathrm{~nm}$, the temperature was increased to $50 \mathrm{~K}, 75 \mathrm{~K}, 85 \mathrm{~K}$ and $90 \mathrm{~K}$. After the light was switched off, the temporal evolution of $\chi_{m} T$ was recorded, showing a small increase, reaching after one hour a stationary state whose HS fraction value is lower than that of the HS-LS plateau (Figure S9). Interestingly, and contrary to the thermal relaxation of the HS fraction after green light irradiation, none of the relaxation curves starting from the T(reverse-LIESST) reached the plateau. Even those performed at high temperature $(\sim 90 \mathrm{~K})$ saturated after one hour below the plateau region. Moreover, we observed that the T(reverse-LIESST) is weakly influenced by the temperature sweep rate change. Taken together, these results suggest that the LS state induced by the near-infrared irradiation most likely corresponds to a stable state. On heating, this state undergoes a spin transition at $\mathrm{T}_{1 / 2} \sim 85 \mathrm{~K}$, during which presumably only Fe 2 sites convert from LS to HS, while Fe1 remain trapped in the LS state. Thus, reverse-LIESST process enabled access to a hidden stable LS state, which was unreachable on cooling from the high-temperature phase. This particular point will be discussed in the section devoted to the photo-crystallographic studies.

Let us briefly summarize the key multi-stability features of the current system at lowtemperature, according to the data of LIESST and reverse-LIESST experiments: the stability of the three macroscopic configurations is different. The photo-induced (green light) HS-HS state is metastable and then relaxes back to the intermediate configuration according to a dynamical process described by a self-accelerated model. The HS-LS state (plateau) remains stable or metastable with an extremely long lifetime, as confirmed by the relaxation kinetics from the photo-induced HS-HS state which stop at the HS-LS plateau and do not cross this limit. Furthermore, relaxation kinetics (time evolution), recorded at $75 \mathrm{~K}, 85 \mathrm{~K}$ and $90 \mathrm{~K}$ in the intermediate state during 4 hours, did not show any change in the $\chi_{m} T$ product (Figure S10). This very strong metastability of the intermediate state should be correlated to the above mentioned distortion of the structure at low-temperature, which generates an elastic energy barrier around $\mathrm{Fe} 2$ sites, thus enhancing their metastable character. Finally, the existence of the stable LS-LS state paves the way for an interplay and photo-multi-switching between these three states. Indeed, at $10 \mathrm{~K}$, the HS-LS intermediate state can be either switched to the HS-HS or the LS-LS states, depending on the wavelength used. Moreover, the LS-LS 
configuration can be directly reached from the HS-HS state by irradiation at $830 \mathrm{~nm}$ and reversely the HS-HS configuration is obtained by irradiation of the LS-LS state at $510 \mathrm{~nm}$ (Figure 7). This bidirectional photo-switching remains effective until $50 \mathrm{~K}$. At $50 \mathrm{~K}$, green light excitation during 6 hours, either from HS-LS or LS-LS states leads to the same photostationary state with $\chi_{m} T$ product equal to $2.27 \mathrm{~cm}^{3} \cdot \mathrm{K} \cdot \mathrm{mol}^{-1}$. This value is very close to the $\chi_{m} T$ value of the intermediate plateau. Above this temperature, one enters the light-induced thermal hysteresis of the direct-LITH region (see Figure 8a) and the photoexcitation using green light irradiation from the HS-LS state stops at the quasi-static branch (black curve) of the LITH. In contrast, the photoexcitation from HS-LS to the LS-LS state at $50 \mathrm{~K}$ using red light leads to an appreciable magnetic change from 2.27 to $1.07 \mathrm{~cm}^{3} \cdot \mathrm{K}^{\prime} \mathrm{mol}^{-1}$ (Figure $8 \mathrm{~b}$ ), because we are outside the quasi-static reverse-LITH curve.

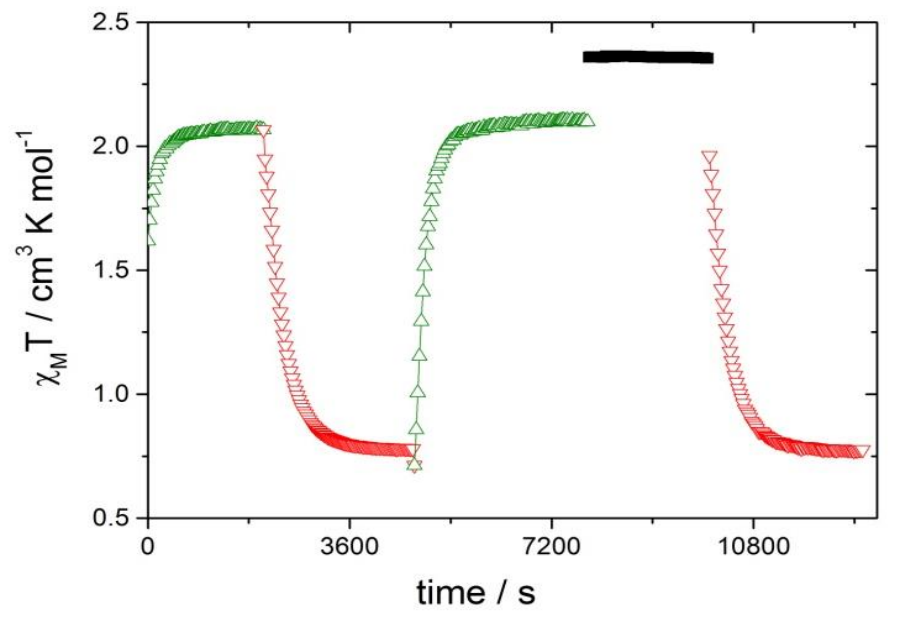

Figure 7. Temporal evolution of the $\chi_{m} T$ product under successive irradiations $(510 \mathrm{~nm}(\Delta)$ and $830 \mathrm{~nm}(\nabla))$ at $10 \mathrm{~K}$ between the HS-HS and LS-LS states. The filled black squares stand for a kinetic recorded in the dark, demonstrating that the decrease observed under $830 \mathrm{~nm}$ irradiation is not due to thermal relaxation effects. Used power intensity was $6 \mathrm{~mW} . \mathrm{cm}^{-2}$.

Thus, under permanent light irradiation, upon warming and cooling, the competition between the non-linear relaxation and the light excitation leads to a photo-induced instability, that manifests itself through the presence of LITH curves for both irradiation wavelengths (Figure 8). ${ }^{24,26}$ Since these curves are the results of an equilibrium between population and relaxation they are very sensitive to the measurement timescale. To have access to the equilibrium curve, the quasi-static curve, several photostationary points were recorded at several temperatures along the cooling and warming branches. Under light irradiation, the temperature was set at the desired value, and the temporal evolution of $\chi_{m} T$ under light was recorded. Recording several isothermal relaxations under green and red light irradiations on the direct- and reverse- 
LITH curves, respectively, (see Figures $8 \mathrm{a}$ and $8 \mathrm{~b})^{27}$ led to reach the photo-stationary states. From these photostationary point, the envelope of their respective quasi-static LITH loops (black curves) can be drawn, whose widths are estimated to be $4 \mathrm{~K}$ and $25 \mathrm{~K}$. Furthermore, the warming branch of the quasi-static hysteresis (black curve in Figure 8b) also matches very well that of the dark (Figure S9). This is confirmed by the isothermal temporal evolution of $\chi_{\mathrm{m}} \mathrm{T}$ along the heating branch of the reverse-LITH curve, from the LS-LS state, that matches perfectly the ones recorded in the dark (Figure S11). The absence of any influence of $830 \mathrm{~nm}$ irradiation on the thermal evolution and the relaxation kinetics of the LS-LS state, strengthens the argument that the heating branch of the reverse-LITH curve describes the thermallyinduced spin transition of a hidden stable LS-LS state towards the LS-HS phase around $80 \mathrm{~K}$. On cooling from the plateau region, near-infrared irradiation favoured the occurrence of the reversible HS-LS $\rightarrow$ LS-LS transition around $50 \mathrm{~K}$. This way, a closed thermal hysteresis loop related to the transition of $\mathrm{Fe} 2$ center is observed, while in the dark the system stays desperately trapped in the intermediate state. This behaviour reveals the presence of a hidden thermal hysteresis in the HS-LS plateau, which was not accessible in the thermally-induced process.

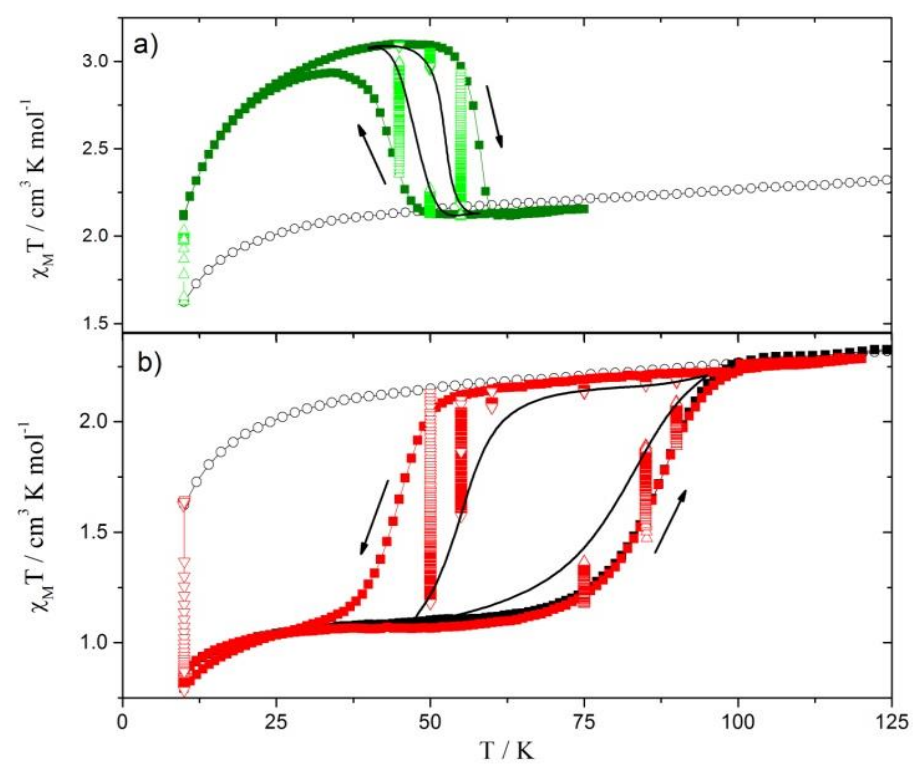

Figure 8 a) (resp. b)) thermal evolution of the $\chi_{\mathrm{m}} \mathrm{T}$ product in the dark (o) and under green (resp. red) light irradiation ( $\square$ ) at $510 \mathrm{~nm}$ (resp. (匹) at $830 \mathrm{~nm}$ ) in warming and cooling modes. Temporal evolution of the photo-converted HS fraction in isothermal conditions $(\mathrm{T}=$ 45, 50 and $55 \mathrm{~K}$ ) (resp. 75, 85 and $90 \mathrm{~K}$ ) towards photo-stationary states: on heating from the HS-LS $(\Delta)$ (resp. LS-LS, $(\Delta)$ ) and on cooling the HS-HS $(\nabla)$ (resp. HS-LS $(\nabla)$ at 60, 55 and $50 \mathrm{~K}$ states. The black curves stand for the quasi-static hysteresis loop which are indicative of the real static loop. The temperature scan rate was $0.4 \mathrm{~K} \cdot \mathrm{min}^{-1}$ for both experiments and power intensity was $6 \mathrm{~mW} \cdot \mathrm{cm}^{-2}$. 
To study the dynamical properties of the corresponding cooling branch of the reverse LITH loop, we carried out partial excitations using near infrared light at $10 \mathrm{~K}$, followed by the thermal relaxation of the magnetic response in the dark. The obtained results are summarized in Figure 9. All partial reverse-LIESST photo-excitations (blue, red and olive curves) of $\mathrm{Fe} 2$ centers from HS to LS, show on heating, typical trends of thermal relaxation of a part of the photo-converted Fe2 HS fraction towards the LS state, with a relaxation temperature (located at the inflection points of the curves, dashed line) which decreases as the photo-excitation progresses. Besides, the location of the relaxation temperatures, represented by the dashed black curve in Figure 9, matches quite well that of the photo-stationary states, depicted in Figure $8 b$ (full black line).

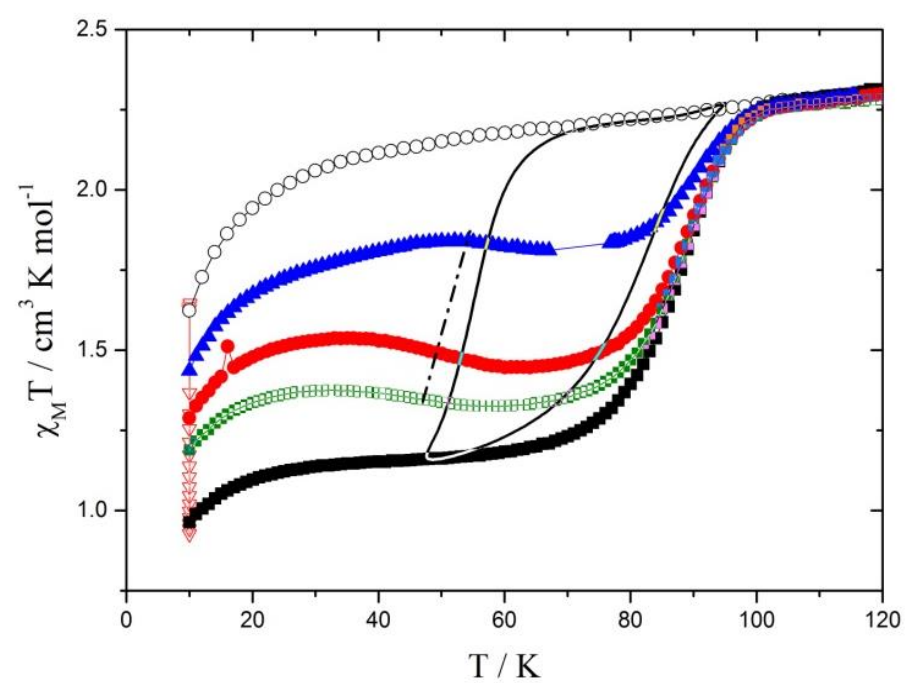

Figure 9. Thermal evolution of the magnetic response in the dark, subsequent to partial photo-excitations using $830 \mathrm{~nm}$ wavelength for $4 \mathrm{~min}$ (blue), $6 \mathrm{~min}$ (red) and $8 \mathrm{~min}$ (green) light irradiation. All curves show first an increase of the magnetic signal due to zero field splitting effects, followed by a thermal relaxation of the photo-converted HS fraction towards the "LS" state, before to join the upper heating branch at which the system reaches the limit of the metastability. The temperature sweep rate was $0.4 \mathrm{~K} \cdot \mathrm{min}^{-1}$. The dashed black curve, representing the locus of relaxation temperatures (inflection points). The black hysteresis curve stands for the quasi-static hysteresis loop obtained in figure $8 \mathrm{~b}$ (power intensity $=6$ $\left.\mathrm{mW} \cdot \mathrm{cm}^{-2}\right)$.

In the light of these photomagnetic studies, the crystal structure has been further derived at $10 \mathrm{~K}$ in the three relevant configurations, i.e. in the HS-LS state upon cooling from $120 \mathrm{~K}$, after irradiation with $532 \mathrm{~nm}$ solid state laser, and after irradiation with $808 \mathrm{~nm}$ diode laser. These three states are called IP2, HS2, and LS hereafter. The structural topology described 
above is retained at $10 \mathrm{~K}$ in all the three states, no space group change occurs. Upon temperature decrease from $120 \mathrm{~K}$ (IP1) to $10 \mathrm{~K}$ (IP2), only marginal modifications attributed to thermal contraction effects occurred; the mean Fe1-N and Fe2-N bond distances only slightly decreased within standard deviations. Upon irradiation with $808 \mathrm{~nm}$ from IP2 phase, the Fe2-N bond distances drastically-decreased to a mean value of 1.964(3) $\AA$, which is characteristic of a complete HS to LS spin state change for this Fe2 site, while Fe1 remained in the LS state, in agreement with the photomagnetic data. In contrast, irradiation with $532 \mathrm{~nm}$ from the IP2 phase led to a large increase in the Fe1-N bond distances, indicative of a LS to HS spin state change for Fe1. Altogether, the crystallographic results (Table 1) confirm the multi-directional photo-switching features, observed in photomagnetic studies, between the three states LS-LS, LS-HS, and HS-HS at $10 \mathrm{~K}$. Although, not shown here, reversible direct photo-switching between photo-excited HS-HS and LS-LS states were also possible in photocrystallography. In all the three states, the difference in angular distortion between Fe1 and $\mathrm{Fe} 2$, that is a higher distortion for $\mathrm{Fe} 2$, was preserved, especially in the HS2 state while $\mathrm{Fe} 1$ and $\mathrm{Fe} 2$ are both assigned a HS state. The corrugation of the 2D layer, as evidenced by the tilt of the $\mathrm{Fe} 1 \mathrm{~N}_{4}$ plane with respect to the $\mathrm{Fe} 2 \mathrm{~N}_{4}$ plane, increases continuously from the LS $\left(19.3(2)^{\circ}\right)$ to IP2 $\left(22.4(2)^{\circ}\right)$ to HS2 $\left(28.6(2)^{\circ}\right)$ states (Figure 10). As shown by de square distortion parameter Sd (see Table 2 for its definition), the deformation of the pseudo-squares around the iron atoms within the 2D layers is always higher around Fe2 and much reduced in the LS and HS states compared to the IP state, which exhibits therefore the most important elastic strain (Table 2 and Figures 3a, S6, S7, S12 and S13). The latter is most likely at the origin of the stabilization of the ordered antiferro-elastic HS-LS structure of the plateau region. The corresponding Fe...Fe, and Pt...Pt distances (Table 2 and Figures S7, S12 and S13) range from 7.064(1) to 7.662(1) $\AA$ in the IP2 state. It is interesting to note that in each case, the difference within $\mathrm{Fe} . . \mathrm{Fe}$ distances is much smaller than those within Pt...Pt distances, which then absorb a part of the structure change resulting from the HS to LS conversion of Fe1. This is obvious for the IP2 case, where Pt...Pt distances range from $7.064(1)$ to $7.662(1) \AA$, while the Fe...Fe distances range only from 7.248(1) to 7.308(1) $\AA$.

Table 2. Fe...Fe, Pt...Pt distances $(\AA)$ and squares distortion $(\mathrm{Sd}, \%)$ in the pseudo-squares within the 2D layers

\begin{tabular}{c|ccccc}
\hline & 10 K IP2 & 10 K LS & 10K HS2 & 120K IP1 & 296K HS1 \\
\hline Fe1...Fe1 & $7.248(1)$ & $7.084(1)$ & $7.396(1)$ & $7.247(2)$ & $7.404(2)$ \\
$\mathrm{Fe} 1 \ldots \mathrm{Fe} 2$ & $7.308(1)$ & $7.220(1)$ & $7.364(1)$ & $7.319(2)$ & $7.409(2)$
\end{tabular}




\begin{tabular}{c|ccccc}
$\mathrm{Fe} 2 \ldots \mathrm{Fe} 2$ & $7.248(1)$ & $7.084(1)$ & $7.396(1)$ & $7.247(2)$ & $7.404(2)$ \\
$\mathrm{Pt} . . \mathrm{Pt}^{\mathrm{a}}$ & $7.064(1)$ & $7.218(1)$ & $7.362(1)$ & $7.073(2)$ & $7.399(2)$ \\
$\mathrm{Pt} . . \mathrm{Pt}^{\mathrm{b}}$ & $7.662(1)$ & $7.296(1)$ & $7.506(1)$ & $7.669(2)$ & $7.519(2)$ \\
$\mathrm{Pt} . . \mathrm{Pt}^{\mathrm{c}}$ & $7.248(1)$ & $7.084(1)$ & $7.396(1)$ & $7.247(2)$ & $7.404(2)$ \\
$\mathrm{Sd}(\mathrm{Fe} 1)^{\mathrm{d}}$ & $2.54(3)$ & $1.89(3)$ & $0.46(3)$ & $2.40(6)$ & $0.07(6)$ \\
$\mathrm{Sd}(\mathrm{Fe} 2)^{\mathrm{d}}$ & $5.71(3)$ & $2.99(3)$ & $1.49(3)$ & $5.82(6)$ & $1.55(6)$ \\
\hline
\end{tabular}

${ }^{a}$ within Fe1-Pt-Fe1-Pt pseudo square, ${ }^{b}$ within Fe2-Pt-Fe2-Pt pseudo square, ${ }^{c}$ within Fe1-PtFe2-Pt pseudo square. ${ }^{\text {d }} \mathrm{Sd}$ is defined as the difference of the both side of the pseudo square around $\mathrm{Fe} 1$ and $\mathrm{Fe} 2$ respectively divided by the common side between both squares. This

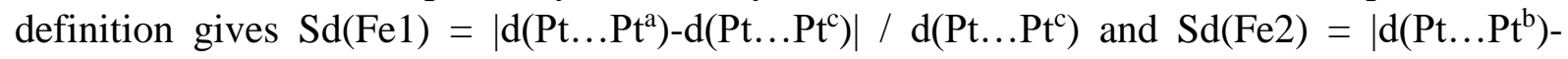
$\mathrm{d}\left(\mathrm{Pt} \ldots \mathrm{Pt} \mathrm{t}^{\mathrm{c}}\right) \mid / \mathrm{d}\left(\mathrm{Pt} \ldots \mathrm{Pt} \mathrm{t}^{\mathrm{c}}\right)$.

An additional inspection of the temperature changes of the Fe...Fe and Pt...Pt distances shows that, from the outset at ambient temperature, the three Pt-Fe-Pt-Fe pseudo-squares show that the largest Pt-Pt distance is systematically obtained for Fe2-Pt-Fe2-Pt pseudosquare. This introduces an elastic frustration ${ }^{18}$ maintaining the $\mathrm{Fe} 2$ site in the HS state. On decreasing temperature from $296 \mathrm{~K}$, and contrary to the two others, the largest Pt...Pt distance first increases at $120 \mathrm{~K}$, before to collapse at lower temperatures. Looking more closely to the Fe-N distances between the three states, this elastic distortion becomes obvious. The average $\mathrm{Fe}-\mathrm{N}$ distances do not change significantly if the corresponding spin state does not change. That is to say $\langle\mathrm{Fe} 1-\mathrm{N}\rangle$ is identical for LS and IP2, while $\langle\mathrm{Fe} 2-\mathrm{N}\rangle$ is identical for HS and IP2. On the contrary, individual Fe-N distances exhibit significant changes of about two to three standard deviations. This results from the local distortion of the Fe1 (resp. $\mathrm{Fe} 2$ ) octahedron as a response to the spin state change of Fe2 (resp. Fe1) from IP2 to LS (resp. $\mathrm{HS} 2)$. The indirect elastic distortion is then mediated by the bridging $[\mathrm{Pt}(\mathrm{CN}) 4]^{2-}$ entities within the $2 \mathrm{D}$ lattice.

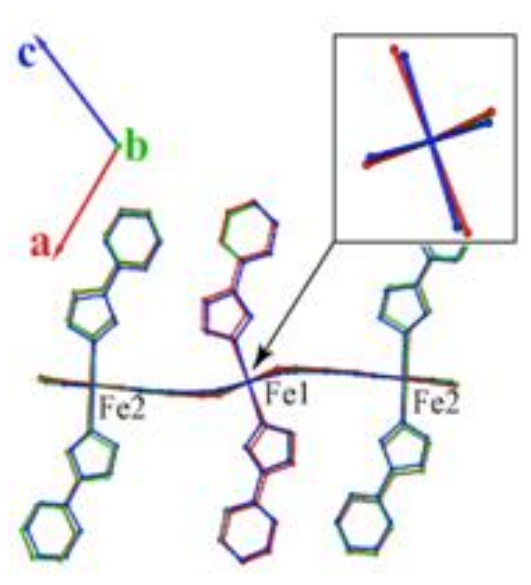

(a)

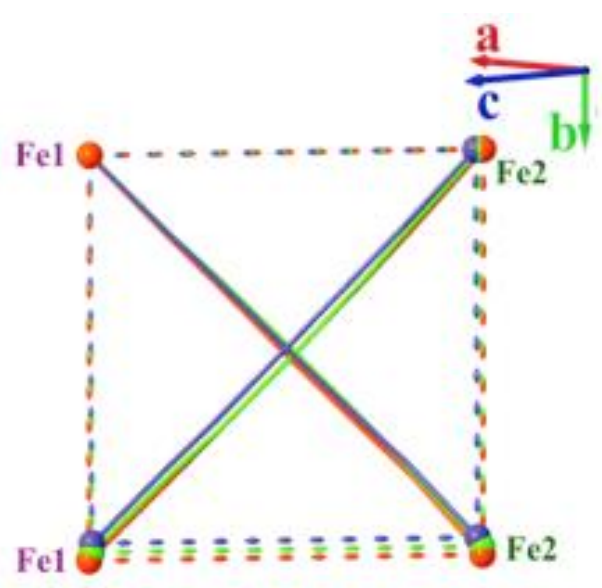

(b) 
Figure 10. Overlay of the HS2 (red), IP2 (green) and LS (blue) structures at $10 \mathrm{~K}$ (a) along the $\left[\begin{array}{lll}0 & 1 & 0\end{array}\right]$ direction, and (b) along the [- $\left.\begin{array}{lll}-1 & 0 & 1\end{array}\right]$ direction, showing the difference in corrugation. On the left, note especially the rotation of the central $\mathrm{Fe} 1$ basal plane (corresponding to P1 in Figure 5).

\section{口 EXPERIMENTAL SECTION}

General remarks. 2-aminopyridine, diformylhydrazine, potassium tetracyanoplatinate and iron (II) perchlorate were purchased from Sigma-Aldrich and used without further purification. Solvents were used and purified by standard procedures. Elemental analyses were performed by the "Service Central d'Analyses du CNRS", Gif-sur-Yvette, France. Infrared spectra were recorded in the range $4000-50 \mathrm{~cm}^{-1}$ on a FT-IR Brucker ATR Vertex 70 Spectrometer. 
Physical characterizations. Single crystal X-ray studies were performed at $296 \mathrm{~K}$ and $120 \mathrm{~K}$ using a Bruker APEX2 $\kappa$-CCD diffractometer using Mo Ka radiation $(\lambda=0.71073 \AA$ ). $10 \mathrm{~K}$ single crystal diffraction data were collected on a Microfocus Supernova diffractometer equipped with a two dimensional ATLAS detector, using Mo K $\alpha$ radiation, and a Helijet He open flow cryosystem. Numerical absorption correction was performed. In situ photoexcitations were carried out using a $808 \mathrm{~nm}$ diode laser (duration $15 \mathrm{~min}$ ), and a $532 \mathrm{~nm}$ solid state laser (duration $20 \mathrm{~min}$ ) until the photo-stationary state was reached in each case to populate the LS and HS-2 states respectively. The single crystal sample was rotated continuously during excitation to ensure a homogeneous and complete excitation. The corresponding structures were solved by direct methods with the SHELXS program and refined on $\mathrm{F}^{2}$ by weighted full matrix least-squares methods using the SHELXL program. ${ }^{29}$ All non-hydrogen atoms were refined anisotropically, hydrogen atoms were located in difference Fourier maps and treated using a riding model. Crystallographic data and refinement details are provided in Table S1. Room-temperature X-ray powder diffraction spectrum (XRPD) was recorded on a PANalytical Empyrean X-ray powder diffractometer at $45 \mathrm{kV}, 40 \mathrm{~mA}$ with a Cu-target tube (Figure S1). NMR spectra were recorded on a Bruker DRX 300MHz. DSC measurements were performed on a DSC-1/LN2 Mettler Toledo calorimeter setting the heat flow scan rate at $s=0.3 \mathrm{~K} \cdot \mathrm{min}^{-1}$. Magnetic and photomagnetic measurements were performed with a Quantum Design MPMS-XL-5 SQUID magnetometer in the 2-300 $\mathrm{K}$ temperature range with an applied magnetic field of 2 Tesla on assembly of single crystals of compound 1 (with mass of $0.68 \mathrm{mg}$ ). The photomagnetic characterizations of compound 1 were carried out using a set of photodiodes. Irradiation was carried out at $10 \mathrm{~K}$ several times using different wavelengths (i.e. $405 \mathrm{~nm}, 510 \mathrm{~nm}, 650 \mathrm{~nm}, 830 \mathrm{~nm}$ and $980 \mathrm{~nm}$ ) to determine the most efficient conditions to reach a strong photo-conversion yield at photosaturation. A power of $6 \mathrm{~mW} . \mathrm{cm}^{-2}$ at $510 \mathrm{~nm}$ and $10 \mathrm{~mW} \cdot \mathrm{cm}^{-2}$ at $830 \mathrm{~nm}$ were used. LIESST experiments were performed using a $510 \mathrm{~nm}$ wavelength. After switching off the irradiation, the temperature was increased at a rate of $0.4 \mathrm{~K} \cdot \mathrm{min}^{-1}$ up to $100 \mathrm{~K}$, to determine the $\mathrm{T}$ (LIESST) value, ${ }^{24,30,31}$ and over the range $100-300-10 \mathrm{~K}$, to follow the thermal spin transition. The T(LIESST) value was determined as the minimum of the $\partial \chi_{m} T / \partial T$ versus $T$ plot (maximum slope in the $\chi_{m} T$ vs. $T$ plot), corresponding to the temperature at which the light induced HS information is erased. ${ }^{24}$ For the kinetic study, the sample was irradiated at 10 $\mathrm{K}$ until the saturation of the HS fraction and then the temperature was set to 10, 20, 25, 30, 35 and $40 \mathrm{~K}$ and the light was switched off in order to study the relaxation kinetics at these 
temperatures. Reverse-LIESST experiments were performed by irradiating the sample at $10 \mathrm{~K}$ in the plateau region with a $830 \mathrm{~nm}$ Diode-Laser $\left(5 \mathrm{~mW} . \mathrm{cm}^{-2}\right)$, until reaching the saturation of the LS state. All the experiment performed under or after light irradiation were done using a $0.4 \mathrm{Kmn}^{-1}$ temperature scanning rate.

Synthesis of $\left[\mathbf{F e}(\operatorname{trz}-\mathbf{p y})_{2}\left\{\operatorname{Pt}(\mathbf{C N})_{4}\right\}\right] .3 \mathrm{H}_{2} \mathrm{O}$ (1). An aqueous solution $(10 \mathrm{~mL})$ containing the 4-(2-pyridyl)-1,2,4,4H-triazole (146 mg, $1.0 \mathrm{mmol}){ }^{28}$ iron (II) perchlorate $(127.5 \mathrm{mg}, 0.5$ mmol) was left standing overnight. To the resulting light yellow solution, was added $\mathrm{K}_{2}\left[\mathrm{Pt}(\mathrm{CN})_{4}\right] \cdot x \mathrm{H}_{2} \mathrm{O}(188.5 \mathrm{mg}, 0.5 \mathrm{mmol})$ and the mixture was stirred at room temperature. The resulting white precipitate was filtered off and dried (yield $79 \%, 278 \mathrm{mg}$ ). Anal. Calcd for $\mathrm{C}_{18} \mathrm{H}_{18} \mathrm{FeN}_{12} \mathrm{O}_{3} \mathrm{Pt}$ : C, 30.8; H, 2.6; N, $24.0 \%$. Found: C, 31.1; H, 2.6; N, $24.4 \%$ (see Figure S2 for IR data). Single-crystals of 1 were prepared by slow diffusion, in a fine glass tube (3.0 mm diameter) of two aqueous solutions: the first solution was obtained by dissolving $\mathrm{K}_{2}\left[\mathrm{Pt}(\mathrm{CN})_{4}\right] . x \mathrm{H}_{2} \mathrm{O}(37.7 \mathrm{mg}, 0.1 \mathrm{mmol})$ in $10 \mathrm{~mL}$. The second solution was prepared by dissolving $\mathrm{Fe}\left(\mathrm{ClO}_{4}\right)_{2} \cdot x \mathrm{H}_{2} \mathrm{O}(25.5 \mathrm{mg}, 0.1 \mathrm{mmol})$ in a solution $(10 \mathrm{~mL})$ of 4-(2pyridyl)-1,2,4,4H-triazole (29.2 $\mathrm{mg}, 0.2 \mathrm{mmol})$. After standing overnight, a light yellow coloration was appeared. $2 \mathrm{~mL}$ of the $\mathrm{K}_{2}\left[\mathrm{Pt}(\mathrm{CN})_{4}\right] \cdot x \mathrm{H}_{2} \mathrm{O}$ solution was placed in the fine glass tube and similar volume of the yellow solution was added carefully in order to limit mixture of the two solutions. After two days, colorless small fine square crystals of $\mathbf{1}$ were formed by slow diffusion. The IR spectrum of such single crystals is identical to that observed for the white powder of 1 (Figure S3).

\section{- CONCLUSIONS}

A new Hoffman-type framework SCO system [Fe(trz-py $\left.)_{2}\left\{\mathrm{Pt}(\mathrm{CN})_{4}\right\}\right] .3 \mathrm{H}_{2} \mathrm{O}$ has been prepared. Its structure consists of $\left[\mathrm{FePt}(\mathrm{CN})_{4}\right]$ layers separated by interdigited 4(2-pyridyl)-1,2,4,4H-triazole (trz-py) ligands with two inequivalent $\mathrm{Fe}^{\mathrm{II}}$ sites. The 2D network can be described as a succession of $\mathrm{Fe}_{4}$ pseudo-squares which diagonals are formed by $\mathrm{Fe} 1-\mathrm{Pt} 1-\mathrm{Fe} 2$ bridges. Interlayer contacts are assisted by $\pi-\pi$ interactions between the trz-py ligands and a strong hydrogen-bonding network that involves three non-coordinated water molecules. $\left[\mathrm{Fe}(\operatorname{trz}-\mathrm{py})_{2}\left\{\mathrm{Pt}(\mathrm{CN})_{4}\right\}\right] .3 \mathrm{H}_{2} \mathrm{O}$ exhibits an incomplete sharp SCO first-order phase transition centered at $153 \mathrm{~K}$ from a HS-HS to a HS-LS structurally ordered state. Irradiation at $10 \mathrm{~K}$ with green light induces a photo-switching to HS-HS state, characterized by a T(LIESST) value of $52 \mathrm{~K}$. Photomagnetic measurements show that the HS-HS state is metastable, and relaxes back to the 
intermediate HS-LS plateau with self-accelerated relaxations, typical for a highly cooperative SCO system. On the contrary, the irradiation of the HS-LS state with near infrared light is efficient only below the T(LIESST) value of the direct LIESST process, and leads to the emergence of a hidden stable LS-LS state with a markedly different T(reverse-LIESST) value of $85 \mathrm{~K}$. Contrary to the relaxation behavior of the HS-HS state, relaxations from the LS-LS state do not reach the HS-LS plateau, which shows that the LS-LS state is a stable one, and correlatively, the HS-LS state is metastable. The LITH curve associated with the reverse-LIESST process consists in a wide thermal hysteresis whose quasi-static hysteresis loop ranges between 55 and 85 K. All together, these results prove the presence of a hidden hysteresis in the HS-LS plateau, which was not accessible due to the slowing down of the relaxation processes on cooling; the Fe2 site being trapped in the HS state. Irradiation with near infrared light induces its switching to the LS state. The photo-crystallographic investigations for the three $10 \mathrm{~K}$ states indicate that the structural topology is retained and no space group change occur along the bidirectional switching. The very strong metastability of the intermediate HS-LS state originates from antiferroelastic interactions (frustration) within the $\left[\mathrm{FePt}(\mathrm{CN})_{4}\right]$ layers, accommodated by NC-Pt-CN bridges between inequivalent $\mathrm{SCO}$ active $\mathrm{Fe}^{\mathrm{II}}$ sites. This elastic distortion manifests itself in the corrugation of the 2D layers and deformation of the square Fe-Pt-Fe-Pt structural topology. The HS-LS state exhibits the most important elastic distortion, which explains its strong metastability, at the origin of its long lifetime. Most interestingly, these results, and especially the existence of the stable LS-LS state pave the way for an interplay and photo-multi-switching between these three states.

\section{ASSOCIATED CONTENT}

\section{Supporting information}

The Supporting Information is available free of charge on the ACS Publications website at DOI: XXXXX/acs.inorg-chem.XXXXXXX. Syntheses, additional structural characterization, photo-crystallography and photo-induced magnetic characterizations of 1 (PDF). CCDC 1433011 (296K HS1), 1433012 (120K IP-1), and 1434745-1434747 (10K HS-2, 10K IP-2, $10 \mathrm{~K} \mathrm{LS})$ (CIFs). 


\section{AUTHOR INFORMATION}

\section{Corresponding author}

*E-mail: smail.triki@univ-brest.fr

\section{Author Contributions}

The manuscript was written through contributions of all authors.

\section{Notes}

The authors declare no competing financial interest.

\section{- ACKNOWLEDGMENTS}

This work was supported by the CNRS, the Brest University, the "Agence Nationale de la Recherche" (ANR project BISTA-MAT: ANR-12-BS07-0030-01), the Région Aquitaine, the University of Lorraine and University of Paris-Saclay.

\section{口 REFERENCES}

(1) see for example: a) Gütlich, P.; Goodwin, H. A. (Eds.), Top. Curr. Chem. 2004, 233 235; b) Coronado, E.; Galan-Mascaros, J.-R.; Monrabal-Capilla, M.; Garcia-Martinez, J.; Pardo-Ibanez, P., Adv. Mater. 2007, 19, 1359; c) Olguin, J.; Brooker, S.; Coord. Chem. Rev. 2011, 255, 203; d) Halcrow, M. A., Chem. Soc. Rev. 2011, 40, 4119; e) Prins, F.; Monrabal-Capilla, M.; Osorio, E. A.; Coronado, E.; van der Zant, H. S. J., Adv. Mater. 2011, 23, 1545; f) Gütlich, P.; Gaspar, A.-B.; Garcia, Y., Beilstein J. Org. Chem. 2013, 9, 342; g) Li, Z.-Y.; Dai, J.-W.; Shiota, Y.; Yoshizawa, K.; Kanegawa, S.; Sato, O., Chem. Eur. J. 2013, 19, 12948; h) Halcrow, M. A. (Eds.), Spin-Crossover Materials, Properties and Applications, 2013, John Wiley \& Sons Ltd, Oxford, UK; i) Phan, H.; Benjamin, S. M.; Steven, E.; Brooks, J. S.; Shatruk, M.; Angew. Chem. Int. Ed. Engl. 2015, 127, 823.

(2) a) Decurtins, S.; Gütlich, P.; Köhler, C. P.; Spiering, H.; Hauser, A., Chem. Phys. Lett. 1984, 105, 1; b) Hauser, A., Chem. Phys. Lett. 1986, 124, 543.

(3) a) Poganiuch, P.; Decurtins, S.; Gütlich, P., J. Am. Chem. Soc. 1990, 112, 3270; b) Hinek, R.; Gütlich, P.; Hauser, A., Inorg. Chem. 1994, 33, 567; c) Hinek, R.; Spiering, H.; Schollmeyer, D.; Gütlich, P.; Hauser, A., Chem. Eur. J. 1996, 2, 1427; d) Hinek, R.; Spiering, H.; Gütlich, P.; Hauser, A., Chem. Eur. J. 1996, 2, 1435; Kusz, J.; Spiering, H.; Gütlich, P., J. Appl. Cryst. 2001, 34, 229. 
(4) Feng, X.; Mathonière, C.; Jeon, I. R.; Rouzières, M.; Ozarowski, A.; Aubrey, M. L.; Gonzalez, M. I.; Clérac, R.; Long, J. R., J. Am. Chem. Soc. 2013, 135, 15880.

(5) a) Létard, J.-F.; Real, J. A.; Moliner, N.; Gaspar, A. B.; Capes, L.; Cador, O.; Kahn, O., J. Am. Chem. Soc. 1999, 121, 10630; b) Chastanet, G.; Carbonera, C.; Mingotaud, C.; Létard, J.-F., J. Mat. Chem. 2004, 14, 3516; c) Ould Moussa, N.; Molnar, G.; Bonhommeau, S.; Zwick, A.; Mouri, S.; Tanaka, K.; Real, J. A.; Bousseksou, A., Phys. Rev. Lett. 2005, 94, 107205(4); d) Ould Moussa, N.; Trzop, E.; Mouri, S.; Zein, S.; Molnar, G.A.; Gaspar, B.; Collet, E.; Buron-Le Cointe, M.; Real, J. A.; Borshch, S.; Tanaka, K.; Cailleau, H.; Bousseksou, A., Phys. Rev. B. 2007, 75, 054101(8).

(6) a) Chakraborty, P.; Enachescu, C.; Humair, A.; Egger, L.; Delgado, T.; Tissot, A.; Guénée, L.; Besnard, C.; Bronisz, R.; Hauser, A., Dalton Trans. 2014, 43, 17786; b) Chakraborty, P.; Pillet, S.; Bendeif, E.-E; Enachescu, C.; Bronisz, R.; Hauser, A., Chem. Eur. J. 2013, 19, 11418; c) Chakraborty, P.; Enachescu, C.; Walder, C.; Bronisz, R.; Hauser, A., Inorg. Chem. 2012, 51, 9714; d) Chakraborty, P.; Bronisz, R.; Besnard, C.; Guénée, L.; Hauser, A., J. Am. Chem. Soc. 2012, 134, 4049.

(7a) Létard, J.-F.; Chastanet, G.; Tokoro, H.; Ohkoshi, S., Curr. Inorg. Chem. 2016, 6, 34; b) Tokoro, H.; Ohkoshi, S., Appl. Phys. Lett. 2008, 93, 021906(2).

(8) Dupouy, G.; Triki, S.; Marchivie, M.; Cosquer, N.; Gómez-García, C. J.; Pillet, S.; Bendeif, E.-E.; Lecomte, C.; Asthana, S.; Létard, J.-F., Inorg. Chem. 2010, 49, 9358.

(9) Setifi, F.; Charles, C.; Houille, S.; Thétiot, F.; Triki, S.; Gómez-García, C. J.; Pillet, S., Polyhedron 2013, 61, 242.

(10) Setifi, F.; Milin, E.; Charles, C.; Thétiot, F.; Triki, S.; Gómez-García, C. J., Inorg. Chem. 2014, 53, 97.

(11) a) Genre, C.; Jeanneau, E.; Bousseksou, A.; Luneau, D.; Borshch, S. A.; Matouzenko, G. S., Chem. Eur. J. 2008, 14, 697; b) Matouzenko, G. S.; Molnár, G.; Bréfuel, N.; Perrin, M.; Bousseksou, A.; Borshch, S. A., Chem. Mater. 2003, 15, 550; c) Moliner, N.; Muñoz, M. C.; Létard, S.; Salmon, L.; Tuchagues, J.-P.; Bousseksou, A.; Real, J. A., Inorg. Chem. 2002, 41, 6997; d) Kahn, O.; Martinez, C. J., Science 1998, $279,44$.

(12) Bao, X.; Shepherd, H. J.; Salmon, L.; Molnar, G.; Tong, M.-L.; Bousseksou, A., Angew. Chem., Int. Ed. 2013, 52, 1198.

(13) a) Martinez, V.; Arcis Castillo, Z.; Muñoz, M. C.; Gaspar, A. B.; Etrillard, C.; Létard, J.-F.; Terekhov, S. A.; Bukin, G. V.; Levchenko, G.; Real, J. A., Eur. J. Inorg. Chem. 2013, 813; b) Ohtani, R.; Yoneda, K.; Furukawa, S.; Horike, N.; Kitagawa, S.; Gaspar, A. B.; Muñoz, M. C.; Real, J. A.; Ohba, M., J. Am. Chem. Soc. 2011, 133, 8600. 
(14) a) Sciortino, N. F.; Neville, S. M.; Létard, J.-F.; Moubaraki, B.; Murray, K. S.; Kepert, C. J., Inorg. Chem. 2014, 53, 7886; b) Otahani, R.; Arai, M.; Ohba, H.; Hori, A.; Takata, M.; Kitagawa, S.; Ohba, M., Eur. J. Inorg. Chem. 2013, 738.

(15) Cobo, S.; Molnar, G.; Real, J. A.; Bousseksou, A., Angew. Chem. Int. Ed. Engl. 2006, 45, 5786.

(16) Bonhommeau, S.; Molnar, G.; Galet, A.; Zwick, A.; Real, J. A.; McGarvey, J.-J.; Bousseksou, A., Angew. Chem. Int. Ed. Engl. 2005, 44, 4069.

(17) Sciortino, N. F.; Scherl-Gruenwald, K. R.; Chastanet, G.; Halder, G. J.; Chapman, K. W.; Létard, J.-F.; Kepert, C. J., Angew. Chem. Int. Ed. Engl. 2012, 51, 10154.

(18) Paez-Espejo, M.; Sy, M.; Boukheddaden, K., J. Am. Chem. Soc. 2016, 138, 3202.

(19 Klein, Y. M.; Sciortino, N. F.; Ragon, F.; Housecroft, C. E.; Kepert, C. J.; Neville, S. M., Chem. Commun. 2014, 50, 3838.

(20) a) Ronayne, K. L.; Paulsen, H.; Höfer, A.; Dennis, A. C.; Wolny, J. A.; Chumakov, A. I.; Schünemann, V.; Winkler, H.; Spiering, H.; Bousseksou, A.; Gütlich, P.; Trautwein, A. X.; McGarvey, J. J., Phys. Chem. Chem. Phys. 2006, 8, 4685; b) Tuchagues, J. P.; Bousseksou, A.; Molnar, G.; McGarvey, J. J.; Varret, F., Top. Curr. Chem. 2004, 235, 85 .

(21) Heating above room temperature $(380 \mathrm{~K}), \mathbf{1}$ loses its solvent water molecules to reach a dehydrated state for which the magnetic study shows a paramagnetic behavior in agreement with the absence of any SCO transition in the 2-380 K temperature range. This dehydrated phase could also be partially obtained by the vacuum made in the SQUID magnetometer as clearly evidenced by a ca. $7 \%$ excess of expected $(50 \%)$ residual fraction of HS Fe(II) ions below $150 \mathrm{~K}$.

(22) Sorai, M.; Seki, S., J. Phys. Chem. Solids 1974, 35, 555.

(23) a) Guionneau, P.; Marchivie, M.; Bravic, G.; Létard, J.-F.; Chasseau, D., Top. Curr. Chem. 2004, 234, 97; b) Marchivie, M.; Guionneau, P.; Létard, J.-F.; Chasseau, D., Acta Cryst. 2005, B61, 25.

(24) Létard, J.-F.; Guionneau, P.; Rabardel, L.; Howard, J. A.-K.; Goeta, A.; Chasseau, D.; Kahn, O., Inorg. Chem. 1998, 37, 4432.

(25) Hauser, A.; Jeftic, J.; Romstedt, H.; Hinek, R.; Spiering, H., Coord. Chem. Rev. 1999, 190-192, 471.

(26) a) Boukheddaden, K.; Shteto, I.; Hôo, B.; Varret, F., Phys. Rev. B 2000, 6, 14796; b) Desaix, A.; Roubeau, O.; Jeftic, J.; Haasnoot, J. G.; Boukheddaden, K.; Codjovi, E.; Linarès, J.; Noguès, M.; Varret, F., Eur. Phys. J. B 1998, 6, 183. 
(27) a) Jeftic, J.; Matsarski, M.; Hauser, A.; Goujon, A.; Codjovi, E.; Linarès, J.; Varret, F.; Polyhedron 2001, 20, 1599; b) Létard, J.-F.; Chastanet, G.; Nguyen, O.; Marcèn, S.; Marchivie, M.; Guionneau, P.; Chasseau, D.; Gütlich, P., "Molecular Magnets Recent Highlights“, Eds W. Linert \& M. Verdaguer, Springer Wien N.-Y. 2003, 49; c) Enachescu, C.; Tanasa, R.; Stancu, A.; Chastanet, G.; Létard, J.-F.; Linares, J.; Varret, F., J. Appl. Phys. 2006, 99, 08J504.

(28) Wiley, R. H.; Hart, A. J., J. Org. Chem. 1953, 18, 1368.

(29) Sheldrick, G. M., Acta Cryst. 2008, A64, 112.

(30) a) Létard, J.-F.; Capes, L.; Chastanet, G.; Moliner, N.; Létard, S.; Real, J. A.; Kahn, O., Chem. Phys. Lett. 1999, 313, 115; b) Marcen, S.; Lecren, L.; Capes, L.; Goodwin, H.A.; Létard, J.-F., Chem. Phys. Lett. 2002, 358, 87; c) Létard, J.-F.; Guionneau, P.; Nguyen, O.; Costa, J.-S.; Marcen, S.; Chastanet, G.; Marchivie, M.; Capes, L., Chem. Eur. J. 2005, 11, 4582; (d) Létard, J.-F, J. Mater. Chem. 2006, 16, 2550.

(31) Létard, J.-F.; Chastanet, G.; Guionneau, P.; Desplanches, C., In Spin-crossover materials: properties and applications, Ed. M. A. Halcrow, John Wiley \& sons, Ltd 2013, 475 . 


\section{TOC entry}

Elastic Frustration Triggering Photo-Induced Hidden Hysteresis and Multistability in a Two-Dimensional Photo-Switchable Hoffman-Like SpinCrossover Metal-Organic Framework

Eric Milin, Véronique Patinec, Smail Triki, El-Eulmi Bendeif, Sébastien Pillet, Mathieu Marchivie, Guillaume Chastanet, Kamel Boukheddaden

We report a 2D Hoffman-like spin-crossover (SCO) material experiencing strong elastic frustration leading to an incomplete spin transition. Under light, a hidden stable low spin state is reached, revealing the existence of a hidden thermal hysteresis and multi-stability features. The existence of these characteristics paves the way for a multi-directional photo-switching and allows potential applications for electronic devices based on ternary digits.

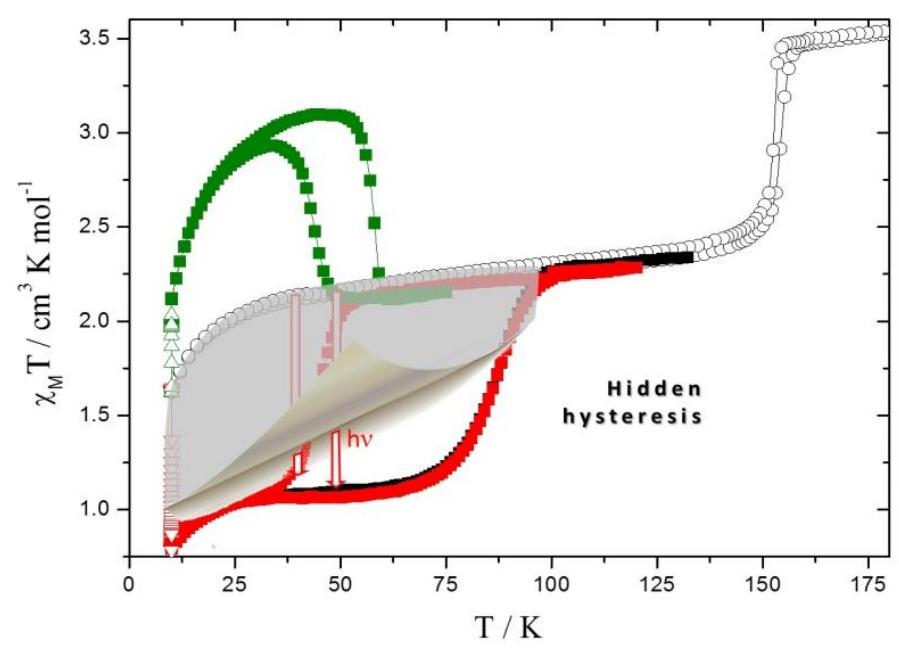

